\title{
Activity monitors for increasing physical activity in adult stroke survivors (Review)
}

Lynch EA, Jones TM, Simpson DB, Fini NA, Kuys SS, Borschmann K, Kramer S, Johnson L, Callisaya ML, Mahendran N, Janssen H, English C, on behalf of the ACTIOnS Collaboration

Lynch EA, Jones TM, Simpson DB, Fini NA, Kuys SS, Borschmann K, Kramer S, Johnson L, Callisaya ML, Mahendran N, Janssen H, English $\mathrm{C}$, on behalf of the ACTIOnS Collaboration.

Activity monitors for increasing physical activity in adult stroke survivors.

Cochrane Database of Systematic Reviews 2018, Issue 7. Art. No.: CD012543.

DOI: 10.1002/14651858.CD012543.pub2.

www.cochranelibrary.com 
TABLE OF CONTENTS

HEADER 1

ABSTRACT

PLAIN LANGUAGE SUMMARY

SUMMARY OF FINDINGS

BACKGROUND

OBJECTIVES

METHODS

Figure 1.

Figure 2.

Figure 3.

RESULTS

DISCUSSION

AUTHORS' CONCLUSIONS

ACKNOWLEDGEMENTS

REFERENCES

CHARACTERISTICS OF STUDIES

DATA AND ANALYSES

Analysis 1.1. Comparison 1 Activity monitor + other intervention vs other intervention alone, Outcome 1 Number of steps per day (x 1000) at end of intervention.

Analysis 1.2. Comparison 1 Activity monitor + other intervention vs other intervention alone, Outcome 2 Time spent on light, moderate, vigorous intensity activity.

Analysis 1.3. Comparison 1 Activity monitor + other intervention vs other intervention alone, Outcome 3 Total time walking at end of intervention.

Analysis 1.4. Comparison 1 Activity monitor + other intervention vs other intervention alone, Outcome 4 Stroke Impact Scale-16 at end of intervention.

ADDITIONAL TABLES

APPENDICES

WHAT'S NEW

CONTRIBUTIONS OF AUTHORS

DECLARATIONS OF INTEREST

SOURCES OF SUPPORT

DIFFERENCES BETWEEN PROTOCOL AND REVIEW

INDEX TERMS 
[Intervention Review]

\title{
Activity monitors for increasing physical activity in adult stroke survivors
}

Elizabeth A Lynch1,2,3, Taryn M Jones ${ }^{4}$, Dawn B Simpson 5 , Natalie A Fini6,7, Suzanne S Kuys ${ }^{8}$, Karen Borschmann²,3, Sharon Kramer², Liam Johnson 2,3, Michele L Callisaya ${ }^{5}$, Niruthikha Mahendran ${ }^{9}$, Heidi Janssen $3,10,11$, Coralie English 3,10 , on behalf of the ACTIOnS Collaboration 12

\begin{abstract}
${ }^{1}$ Adelaide Nursing School, The University of Adelaide, Adelaide, Australia. ${ }^{2}$ The Florey Institute of Neuroscience and Mental Health, University of Melbourne, Heidelberg, Australia. ${ }^{3}$ NHMRC Centre of Research Excellence in Stroke Rehabilitation and Brain Recovery, Florey Institute of Neuroscience and Mental Health \& Hunter Medical Research Institute, Melbourne and Newcastle, Australia. ${ }^{4}$ Faculty of Medicine and Health Sciences, Macquarie University, Sydney, Australia. ${ }^{5}$ Menzies Institute for Medical Research, University of Tasmania, Hobart, Australia. ${ }^{6}$ Physiotherapy Department, The University of Melbourne, Melbourne, Australia. ${ }^{7}$ School of Allied Health, La Trobe University, Melbourne, Australia. ${ }^{8} \mathrm{School}$ of Physiotherapy, Australian Catholic University, Brisbane, Australia. ${ }^{9}$ Discipline of Physiotherapy, Faculty of Health, University of Canberra, Canberra, Australia. 10Priority Research Centre for Stroke and Brain Injury, University of Newcastle, Newcastle, Australia. ${ }^{11}$ Community Aged Care and Hunter Stroke Service, Hunter New England Health, New Lambton Heights, Australia. 12Melbourne; Adelaide; Newcastle; Hobart; Sydney; Brisbane; Canberra, Australia
\end{abstract}

Contact address: Elizabeth A Lynch, Adelaide Nursing School, The University of Adelaide, Adelaide, South Australia, Australia. elizabeth.lynch@adelaide.edu.au.

Editorial group: Cochrane Stroke Group

Publication status and date: Edited (no change to conclusions), published in Issue 10, 2019.

Citation: Lynch EA, Jones TM, Simpson DB, Fini NA, Kuys SS, Borschmann K, Kramer S, Johnson L, Callisaya ML, Mahendran N, Janssen $\mathrm{H}$, English $\mathrm{C}$, on behalf of the ACTIOnS Collaboration. Activity monitors for increasing physical activity in adult stroke survivors. Cochrane Database of Systematic Reviews 2018, Issue 7. Art. No.: CD012543. DOI: 10.1002/14651858.CD012543.pub2.

Copyright $\odot 2019$ The Cochrane Collaboration. Published by John Wiley \& Sons, Ltd.

\section{A B S T R A C T}

\section{Background}

Stroke is the third leading cause of disability worldwide. Physical activity is important for secondary stroke prevention and for promoting functional recovery. However, people with stroke are more inactive than healthy age-matched controls. Therefore, interventions to increase activity after stroke are vital to reduce stroke-related disability.

\section{Objectives}

To summarise the available evidence regarding the effectiveness of commercially available, wearable activity monitors and smartphone applications for increasing physical activity levels in people with stroke.

\section{Search methods}

We searched the Cochrane Stroke Group Trials Register, CENTRAL, MEDLINE, Embase, CINAHL, SPORTDiscus, and the following clinical trial registers: WHO International Clinical Trials Registry Platform, Clinical Trials, EU Clinical Trial Register, ISRCTN Registry, Australian and New Zealand Clinical Trial Registry, and Stroke Trials Registry to 3 March 2018. We also searched reference lists, Web of Science forward tracking, and Google Scholar, and contacted trial authors to obtain further data if required. We did not restrict the search on language or publication status.

\section{Selection criteria}

We included all randomised controlled trials (RCTs) and randomised cross-over trials that included use of activity monitors versus no intervention, another type of intervention, or other activity monitor. Participants were aged 18 years or older with a diagnosis of stroke, in hospital or living in the community. Primary outcome measures were steps per day and time in moderate-to-vigorous intensity activity. 
Secondary outcomes were sedentary time, time spent in light intensity physical activity, walking duration, fatigue, mood, quality of life, community participation and adverse events. We excluded upper limb monitors that only measured upper limb activity.

\section{Data collection and analysis}

We followed standard Cochrane methodology to analyse and interpret the data. At least two authors independently screened titles and abstracts for inclusion. We resolved disagreements by consulting a third review author. We extracted the following data from included studies into a standardised template: type of study, participant population, study setting, intervention and co-interventions, time-frame, and outcomes. We graded levels of bias as high, low, or unclear, and assessed the quality of evidence for each outcome using the GRADE approach.

\section{Main results}

We retrieved 28,098 references, from which we identified 29 potential articles. Four RCTs (in 11 reports) met the inclusion criteria.The sample sizes ranged from 27 to 135 (total 245 participants). Time poststroke varied from less than one week $(n=1)$, to one to three months $(n=2)$, or a median of 51 months $(n=1)$. Stroke severity ranged from a median of one to six on the National Institutes of Health Stroke Scale (NIHSS). Three studies were conducted in inpatient rehabilitation, and one was in a university laboratory. All studies compared use of activity monitor plus another intervention (e.g. a walking retraining programme or an inpatient rehabilitation programme) versus the other intervention alone. Three studies reported on the primary outcome of daily step counts.

There was no clear effect for the use of activity monitors in conjunction with other interventions on step count in a community setting (mean difference (MD) -1930 steps, 95\% confidence interval (CI) -4410 to 550; 1 RCT, 27 participants; very low-quality evidence), or in an inpatient rehabilitation setting (MD 1400 steps, $95 \% \mathrm{Cl}-40$ to 2840; 2 RCTs, 83 participants; very low-quality evidence). No studies reported the primary outcome moderate-to-vigorous physical activity, but one did report time spent in moderate and vigorous intensity activity separately: this study reported that an activity monitor in addition to usual inpatient rehabilitation increased the time spent on moderate intensity physical activity by 4.4 minutes per day ( $95 \% \mathrm{Cl} 0.28$ to $8.52 ; 1 \mathrm{RCT}$, 48 participants; low-quality evidence) compared with usual rehabilitation alone, but there was no clear effect for the use of an activity monitor plus usual rehabilitation for increasing time spent in vigorous intensity physical activity compared to usual rehabilitation (MD 2.6 minutes per day, $95 \% \mathrm{Cl}-0.8$ to $6 ; 1 \mathrm{RCT}, 48$ participants; low-quality evidence). The overall risk of bias was low, apart from high-risk for blinding of participants and study personnel. None of the included studies reported any information relating to adverse effects.

\section{Authors' conclusions}

Only four small RCTs with 274 participants (three in inpatient rehabilitation and one in the community) have examined the efficacy of activity monitors for increasing physical activity after stroke. Although these studies showed activity monitors could be incorporated into practice, there is currently not enough evidence to support the use of activity monitors to increase physical activity after stroke.

\section{PLAIN LANGUAGE SUMMARY}

\section{Do activity monitors help adults with stroke become more physically active?}

\section{Review question}

We reviewed the available evidence regarding the effectiveness of commercially available, wearable devices (for example pedometers, Fitbit, and Garmin watches) and smartphone applications (for example Runkeeper, Fitbit application) for increasing physical activity levels for people with stroke.

\section{Background}

Promoting physical activity is an important health intervention for people with stroke. The association between health and physical activity is well known. People with stroke face additional challenges to engage in sufficient physical activity for health benefits, and are often very inactive. Increasing physical activity levels in stroke survivors in both hospital and community settings is important.

Providing feedback to stroke survivors about their physical activity levels is one strategy that could change their behaviour and increase physical activity levels. Wearable devices that count steps or measure activity, or smartphone applications that provide feedback about physical activity could be useful. Understanding how effective such devices are to increase physical activity has the potential to benefit all people after stroke.

\section{Study characteristics}

We included four trials in this review, comprising 245 participants, ranging in age from 22 to 92 years. Three trials measured physical activity outcomes after the treatment period. Trials were conducted in hospital and community settings. All participants were able to communicate and provide informed consent, and all were able to walk at least five steps without supervision or assistance. The experimental groups in the trials received feedback at least daily on the number of steps taken.

\section{Search date}

Activity monitors for increasing physical activity in adult stroke survivors (Review) 
We searched for studies up to 3 March 2018.

\section{Key results}

We found that the use of wearable activity monitors to provide feedback on physical activity did not increase physical activity levels in people with stroke. No conclusions could be drawn regarding the influence of stroke severity, walking ability, stroke survivor age, or time poststroke on the outcomes. The four included studies were conducted in different settings, and used different outcome measures, which limited the ability to combine data. No study reported whether the use of physical activity monitors was harmful. More research is needed to determine if they are effective.

\section{Quality of the evidence}

Using the GRADE approach, the quality of the evidence was low to very low, due to the small number of studies, small sample sizes, and because no study was able to blind the participants or the therapists delivering the intervention (they were aware that a device was being used and aware of the feedback that was being provided by the device). 
SUMMARY OF FINDINGS

Summary of findings for the main comparison. Activity monitor plus other intervention compared to other intervention alone for increasing physical activity in adult community dwelling stroke survivors

Activity monitor plus other intervention compared to other intervention alone for increasing physical activity in adult community dwelling stroke survivors

Patient or population: increasing physical activity in adult community dwelling stroke survivors

Setting: community

Intervention: activity monitor plus other intervention

Comparison: other intervention

\begin{tabular}{|c|c|c|c|c|c|c|}
\hline \multirow[t]{2}{*}{ Outcomes } & \multicolumn{2}{|c|}{ Anticipated absolute effects* $(95 \% \mathrm{Cl})$} & \multirow{2}{*}{$\begin{array}{l}\text { Relative ef- } \\
\text { fect } \\
(95 \% \mathrm{Cl})\end{array}$} & \multirow{2}{*}{$\begin{array}{l}\text { № of partici- } \\
\text { pants } \\
\text { (studies) }\end{array}$} & \multirow{2}{*}{$\begin{array}{l}\text { Quality of the } \\
\text { evidence } \\
\text { (GRADE) }\end{array}$} & \multirow[t]{2}{*}{ Comments } \\
\hline & Risk with other intervention & $\begin{array}{l}\text { Risk with activity } \\
\text { monitor plus other } \\
\text { intervention }\end{array}$ & & & & \\
\hline $\begin{array}{l}\text { Number of steps per day ( } x \\
1000) \text { at end of intervention (> } \\
6 \text { months post-stroke) }\end{array}$ & $\begin{array}{l}\text { The mean number of steps per day } \\
(x 1000) \text { at end of intervention }(>6 \\
\text { months post-stroke) was } 7.09 \text { Steps } \\
(x 1000)\end{array}$ & $\begin{array}{l}\text { MD } 1.93 \text { Steps }(x 1000) \\
\text { lower } \\
\text { ( } 4.41 \text { lower to } 0.55 \\
\text { higher) }\end{array}$ & - & $\begin{array}{l}27 \\
(1 \mathrm{RCT})\end{array}$ & $\begin{array}{l}\oplus \ominus \ominus \ominus \\
\text { Very low } 123\end{array}$ & $\begin{array}{l}\text { Based on a single } \\
\text { small study in which } \\
\text { participants and } \\
\text { personnel were not } \\
\text { blinded }\end{array}$ \\
\hline $\begin{array}{l}\text { Time spent in MVPA (minutes) } \\
\text { at the end of the intervention } \\
\text { (> } 6 \text { months post-stroke) - not } \\
\text { reported }\end{array}$ & - & - & - & - & - & \\
\hline $\begin{array}{l}\text { Sedentary time (minutes) at } \\
\text { the end of the intervention (> } \\
6 \text { months post-stroke) - not } \\
\text { reported }\end{array}$ & - & - & - & - & - & \\
\hline $\begin{array}{l}\text { Time spent in light intensi- } \\
\text { ty activity (minutes) at the } \\
\text { end of the intervention (> } 6 \\
\text { months post-stroke) - not re- } \\
\text { ported }\end{array}$ & - & - & - & - & - & \\
\hline $\begin{array}{l}\text { Total time walking (minutes) } \\
\text { at end of intervention ( }>6 \\
\text { months post-stroke) }\end{array}$ & $\begin{array}{l}\text { The mean total time walking (min- } \\
\text { utes) at end of intervention ( }>6 \\
\text { months post-stroke) was } 141 \text { min- }\end{array}$ & $\begin{array}{l}\text { MD } 39 \text { minutes per day } \\
\text { lower } \\
\text { (83.9 lower to } 5.9 \text { high- }\end{array}$ & - & $\begin{array}{l}27 \\
(1 \mathrm{RCT})\end{array}$ & $\begin{array}{l}\oplus \ominus \Theta \Theta \\
\text { Very low } 123\end{array}$ & $\begin{array}{l}\text { Based on a single } \\
\text { small study in which } \\
\text { participants and }\end{array}$ \\
\hline
\end{tabular}


${ }^{*}$ The risk in the intervention group (and its 95\% confidence interval) is based on the assumed risk in the comparison group and the relative effect of the intervention (and its $95 \% \mathrm{Cl}$ ).

Cl: Confidence interval; RR: Risk ratio; OR: Odds ratio;

\section{GRADE Working Group grades of evidence}

High certainty: We are very confident that the true effect lies close to that of the estimate of the effect

Moderate certainty: We are moderately confident in the effect estimate: The true effect is likely to be close to the estimate of the effect, but there is a possibility that it is

substantially different

Low certainty: Our confidence in the effect estimate is limited: The true effect may be substantially different from the estimate of the effect

Very low certainty: We have very little confidence in the effect estimate: The true effect is likely to be substantially different from the estimate of effect

1 Risk of bias: participants and personnel were not blinded

2 Risk of bias: it was unclear if the sequence was generated randomly and if allocation was concealed

3 Imprecision: the study included a small sample and confidence intervals were wide

\section{Summary of findings 2. Activity monitor plus other intervention compared to other intervention alone for increasing physical activity in adult stroke} survivors during inpatient rehabilitation

Activity monitor plus other intervention compared to other intervention alone for increasing physical activity in adult stroke survivors during inpatient rehabilitation

Patient or population: increasing physical activity in adult stroke survivors during inpatient rehabilitation Setting: inpatient rehabilitation

Intervention: activity monitor plus other intervention

Comparison: other intervention alone

\begin{tabular}{|c|c|c|c|c|c|c|}
\hline \multirow[t]{2}{*}{ Outcomes } & \multicolumn{2}{|l|}{ Anticipated absolute effects ${ }^{\star}(95 \% \mathrm{CI})$} & \multirow{2}{*}{$\begin{array}{l}\text { Relative ef- } \\
\text { fect } \\
(95 \% \mathrm{Cl})\end{array}$} & \multirow{2}{*}{$\begin{array}{l}\text { № of partici- } \\
\text { pants } \\
\text { (studies) }\end{array}$} & \multirow{2}{*}{$\begin{array}{l}\text { Quality of the } \\
\text { evidence } \\
\text { (GRADE) }\end{array}$} & \multirow[t]{2}{*}{ Comments } \\
\hline & Risk with other intervention alone & $\begin{array}{l}\text { Risk with Activity } \\
\text { monitor plus other } \\
\text { intervention }\end{array}$ & & & & \\
\hline $\begin{array}{l}\text { Number of } \\
\text { steps per day ( } x \\
1000) \text { at end of } \\
\text { intervention (< } \\
6 \text { months post- } \\
\text { stroke) }\end{array}$ & $\begin{array}{l}\text { The mean number of steps per day } \\
(x 1000) \text { at end of intervention }(<6 \\
\text { months post-stroke) was } 3.1 \text { steps ( } x \\
1000)\end{array}$ & $\begin{array}{l}\text { MD } 1.4 \text { steps ( } x 1000) \\
\text { higher } \\
\text { (0.04 lower to } 2.84 \\
\text { higher) }\end{array}$ & - & $\begin{array}{l}83 \\
\text { (2 RCTs) }\end{array}$ & $\begin{array}{l}\oplus \Theta \Theta \Theta \\
\text { Very low } 123\end{array}$ & $\begin{array}{l}\text { Based on } 2 \text { small studies with } \\
\text { heterogeneous results in which } \\
\text { patients and personnel were not } \\
\text { blinded and limited information } \\
\text { was provided about randomisa- } \\
\text { tion and allocation procedures }\end{array}$ \\
\hline
\end{tabular}




\begin{tabular}{|c|c|c|c|c|c|}
\hline \multirow{2}{*}{$\begin{array}{l}\text { Time spent in } \\
\text { MVPA (minutes) } \\
\text { at the end of } \\
\text { the intervention } \\
\text { (<6 months } \\
\text { post-stroke) - } \\
\text { not reported } \\
\text { Sedentary time } \\
\text { (minutes) at the } \\
\text { end of the in- } \\
\text { tervention (<6 } \\
\text { months post- } \\
\text { stroke) - not re- } \\
\text { ported }\end{array}$} & - & - & - & - & \\
\hline & - & - & - & - & \\
\hline $\begin{array}{l}\text { Time spent on } \\
\text { light intensity } \\
\text { physical activi- } \\
\text { ty (minutes) at } \\
\text { the end of the } \\
\text { intervention (< } \\
6 \text { months post- } \\
\text { stroke) (Time } \\
\text { spent on light } \\
\text { intensity phys- } \\
\text { ical activity } \\
\text { (minutes)) }\end{array}$ & $\begin{array}{l}\text { The mean time spent on light intensity } \\
\text { physical activity (minutes) at the end } \\
\text { of the intervention ( }<6 \text { months post- } \\
\text { stroke) was } 113.7 \mathrm{~min} / \text { day }\end{array}$ & $\begin{array}{l}\text { MD } 25.8 \mathrm{~min} / \text { day } \\
\text { higher } \\
\text { (0.48 higher to } 51.1 \\
\text { higher) }\end{array}$ & $\begin{array}{l}48 \\
(1 \mathrm{RCT})\end{array}$ & $\begin{array}{l}\oplus \oplus \ominus \ominus \\
\text { Low } 13\end{array}$ & $\begin{array}{l}\text { Based on a single small study in } \\
\text { which participants and personnel } \\
\text { were not blinded }\end{array}$ \\
\hline $\begin{array}{l}\text { Total time } \\
\text { walking (min- } \\
\text { utes) at end of } \\
\text { intervention (< } \\
6 \text { months post- } \\
\text { stroke) }\end{array}$ & $\begin{array}{l}\text { The mean total time walking (minutes) } \\
\text { at end of intervention ( }<6 \text { months } \\
\text { post-stroke) was } 71.5 \mathrm{~min} / \text { day }\end{array}$ & $\begin{array}{l}\text { MD } 4.4 \text { min/day high- } \\
\text { er } \\
\text { (11.52 lower to } 20.32 \\
\text { higher) }\end{array}$ & $\begin{array}{l}35 \\
(1 \mathrm{RCT})\end{array}$ & $\begin{array}{l}\oplus \oplus \ominus \ominus \\
\text { Low } 13\end{array}$ & $\begin{array}{l}\text { Based on a single small study in } \\
\text { which participants and personnel } \\
\text { were not blinded }\end{array}$ \\
\hline
\end{tabular}

${ }^{\star}$ The risk in the intervention group (and its $95 \%$ confidence interval) is based on the assumed risk in the comparison group and the relative effect of the intervention (and its $95 \% \mathrm{Cl}$ ).

\section{Cl: Confidence interval; RR: Risk ratio; OR: Odds ratio;}

\section{GRADE Working Group grades of evidence}

High certainty: We are very confident that the true effect lies close to that of the estimate of the effect

Moderate certainty: We are moderately confident in the effect estimate: The true effect is likely to be close to the estimate of the effect, but there is a possibility that it is substantially different

Low certainty: Our confidence in the effect estimate is limited: The true effect may be substantially different from the estimate of the effect 
Very low certainty: We have very little confidence in the effect estimate: The true effect is likely to be substantially different from the estimate of effect

1 Risk of bias: participants and personnel were not blinded

2 Heterogeneity: the I-squared statistic suggest that substantial heterogeneity might be present

3 Imprecision: the study included a small sample and confidence intervals were wide 


\section{B A C K G R O U N D}

\section{Description of the condition}

Between 1990 and 2010, the absolute numbers of people living with stroke increased by $84 \%$ worldwide, with stroke now the third leading cause of disability globally (Feigin 2014). As such, the disease burden of stroke is substantial. It has been estimated that $91 \%$ of the burden of stroke is attributable to modifiable risk factors, such as smoking, poor diet, and low levels of physical activity (Feigin 2016). A low level of physical activity (less than four hours per week of activity of at least moderate intensity) is the second highest population-attributable risk factor for stroke, second only to hypertension (O'Donnell 2016). The promotion of physical activity, which has been defined as body movement produced by skeletal muscles resulting in energy expenditure, is therefore, an important health intervention for people with stroke (Caspersen 1985).

The association between health and physical activity is well established. Prolonged, unbroken bouts of sitting is a distinct health risk, independent of time engaged in regular exercise (Healy 2008). There is evidence from cross-sectional and longitudinal studies that high sitting time and low levels of physical activity contribute to poor glycaemic control (Owen 2010). Three systematic reviews and meta-analyses of observational studies have confirmed that after adjusting for other demographic and behavioural risk factors, physical activity is inversely associated with all-cause mortality in men and women (Nocon 2008; Löllgen 2009; Woodcock 2011). Yet despite this knowledge, populations worldwide are becoming more sedentary, and physical inactivity has been labelled a global pandemic (Kohl 2012).

Directly after a stroke, people should be admitted to hospital for co-ordinated care, and commencement of rehabilitation (SUTC 2013). Early rehabilitation after stroke is frequently focused on the recovery of physical independence, particularly walking (Pollock 2014). Recovery after stroke is enhanced by active practice of specific tasks, and greater improvements are seen when people with stroke spend more time in active practice (Veerbeek 2014). Yet findings from research conducted around the world indicate that people in the first few weeks and months after stroke are physically inactive in hospital settings, with around $80 \%$ of the day spent inactive (sitting or lying; West 2012). These high levels of inactivity are concerning, because recovering the ability to walk independently is an important goal of people with stroke (Lord 2004). The reported paucity of standing and walking practice in the early phase after stroke potentially limits the opportunities of people with stroke to optimise functional recovery, particularly for standing and walking goals. Further, physical inactivity may lead to an increased risk of hospital-acquired complications, such as pressure ulcers, pneumonia, and cardiac compromise (Lindgren 2004).

Physical activity levels of people with stroke remain lower than their age-matched counterparts, even when they return to living in the community (English 2016). Community-dwelling stroke survivors spend the vast majority of their waking time sitting down (English 2014). In addition to overcoming the sedentary lifestyles and habits prevalent in many modern societies, people with stroke have additional barriers to physical activity, such as muscle weakness, sensory dysfunction, reduced balance, and fatigue (Billinger 2014). However, early research suggests that increasing physical activity in people with stroke is feasible, and an increase in physical activity levels after stroke may have a positive impact on fatigue, mood, community participation, and quality of life (QoL; Graven 2011; Duncan 2015).

\section{Description of the intervention}

For this review, we considered an activity monitor to be any wearable or portable electronic device that provided feedback (in either real time, or on a regular basis, e.g. daily or weekly) on physical activity. People with stroke could use activity monitors independently, or as an adjunct to therapy. Activity monitors included accelerometers and physical activity applications, which may have been combined with global positioning systems (GPS). Feedback from a physical activity monitor could have included objective measures of activity (e.g. step count, time spent in moderate intensity activity), graphs of daily activity, or encouragement on activity goals (e.g. encouragement to reach 10,000 steps per day).

Accelerometers are non-invasive activity monitors that record 'activity counts', based on acceleration detected across various movement planes (e.g. X, Y, Z planes). The objective measures of activity provided by accelerometers are dependent on the individual device, and include step count, activity duration, total activity counts, and energy expenditure. Accelerometers are classified as 'uniaxial', 'biaxial', or 'triaxial', depending on the number of movement planes across which they detect acceleration. Examples of accelerometers include Fitbit Charge HR, Actigraph, and Sensewear Armband.

Physical activity applications are typically installed on mobile smart devices, which contain powerful embedded sensors, including triaxial accelerometers, GPS, cameras, orientation sensors, and gyroscopes that can be used to deliver continuous and automated real time data to measure and interpret physical activity (Bort-Roig 2014). Applications downloaded on smart devices feature real time feedback based on the user's activity profile, and some applications include an immersive storyline to engage the user in physical activity (Higgins 2016). Illustrations and animations are commonly used to describe how an activity or exercise is to be correctly performed, and some devices can be paired with wearable devices to further enhance the experience and data generated (Higgins 2016). Examples of physical activity applications include Strava Running, Runkeeper, and Fitbit.

GPS technology is now built into many mobile phones, as well as wearable physical activity monitors, and measures activity based on the location of the person. Examples of physical activity GPS systems are Garmin Forerunner and GlobalSat GPS watches.

\section{How the intervention might work}

Activity monitors are inexpensive and readily available to the public. They provide users with easy-to-understand, timely, and contextually relevant information about their physical activity behaviours. Further, many physical activity monitors have been designed to set goals and provide rewards, which are important elements in changing (and maintaining a change in) behaviour (Glynn 2013). Some applications have been designed to act as 'virtual coaches', to encourage and inspire the user. In addition, the capacity for the user's behaviour to be shared via the connectivity capabilities of smart devices can promote social support, feedback, 
and competition via social networking platforms (Nakhasi 2014). Meta-analyses have shown that activity monitors can positively influence multiple health behaviours, including physical activity (Fanning 2012).

Activity monitors are increasingly being used to study physical activity in stroke survivors (Fini 2015). Use of these devices has the potential to be a relatively cheap and easy method of motivating people with stroke, both in the clinical and community setting, to increase physical activity levels for the purposes of maximising poststroke physical function (e.g. walking), and reducing the risk of recurrent stroke via regular exercise.

\section{Why it is important to do this review}

Despite the benefits of time spent in physical activity poststroke, people who have had a stroke spend the majority of their day inactive, regardless of time or setting poststroke (Fini 2017). Commercially available, wearable activity monitoring devices and smartphone applications provide immediate feedback to users on their physical activity levels, and if found to be effective in increasing physical activity, have the potential to benefit all people with stroke. Understanding how effective such devices are in increasing physical activity after stroke will be useful for clinicians and researchers working in stroke prevention and rehabilitation, and for people with stroke who would like to improve their physical activity levels and general well-being.

It is not yet understood whether physical activity monitors alone or with therapist support are effective and feasible in increasing physical activity after stroke. Further, we need to investigate the characteristics of people with stroke (e.g. age, stroke severity) that may influence a person's ability to use an activity monitor independently, or to engage in behaviour change in response to activity monitor feedback. Finally, we need to determine factors related to the activity monitor intervention, such as type of monitor, setting, duration of intervention, intensity, dose, frequency, and mode of feedback for optimum improvements in physical activity after stroke.

\section{OB JECTIVES}

To summarise the available evidence regarding the effectiveness of commercially available, wearable activity monitors and smartphone applications for increasing physical activity levels in people with stroke.

\section{METHODS}

\section{Criteria for considering studies for this review}

\section{Types of studies}

We included randomised controlled trials (RCTs) and randomised cross-over trials.

\section{Types of participants}

Participants were adults (aged 18 and over) with a diagnosis of stroke, who were in a hospital settings or living in the community.

\section{Types of interventions}

We included interventions that examined the effectiveness or feasibility of the use of activity monitors for increasing physical activity levels within hospital or community settings. We excluded upper limb activity monitor interventions that were designed to measure or increase upper limb activity.

We collected data about the type and frequency of feedback delivered during the intervention (including whether the timing of feedback was pre-set or could be controlled by participants), the duration of intervention, and the type of activity monitor used.

We included studies that compared the use of:

- activity monitor versus no intervention;

- activity monitor versus other intervention;

- activity monitor versus different activity monitor;

- activity monitor plus another intervention (e.g. a prescribed exercise programme) versus the other intervention alone.

We excluded studies that compared the use of activity monitor plus another intervention versus no treatment if we could not determine the independent effect of the activity monitor intervention. Given the aim of the review was to determine the effect of physical activity monitors on promoting activity after stroke, we excluded studies that used an activity monitor solely as a research measurement tool.

\section{Types of outcome measures}

\section{Primary outcomes}

- Steps per day. Steps per day is relevant to people with stroke because it is associated with the Activities and Participation domains of the International Classification of Functioning (Eng 2007).

- Time spent in moderate-to-vigorous intensity physical activity (MVPA) at the end of the intervention period (short-term), three months post-intervention (medium-term), and 12 months postintervention (long-term). We had planned to measure time in MVPA in minutes per day and in percentage of waking hours. We had planned to include two methods of calculating MVPA with devices:

* using metabolic equivalents (METS), with MVPA defined as 3 METS or greater, where 1 MET was defined as the energy cost of sitting quietly (Haskell 2007);

* using activity count cutoff points: for example, 1952 counts per minute or greater (using the equations from Freedson and colleagues; Freedson 1998).

Time in MVPA is important because MVPA has a vital role in the prevention of cardiovascular disease and stroke (Tremblay 2010; McDonnell 2013; Billinger 2014). Further, MVPA is inversely associated with all-cause mortality in men and women, after adjustment for other demographic and behavioural risk factors (Nocon 2008; Löllgen 2009; Woodcock 2011). Achieving a total physical activity level of 150 minutes per week of MVPA has been associated with a relative risk reduction (RRR) in all-cause mortality of $16 \%$; a RRR of $26 \%$ was reported for the higher threshold of 300 minutes of MVPA per week (Samitz 2011). Current guidelines recommend that stroke survivors complete at least 150 minutes per week of MVPA (Billinger 2014).

\section{Secondary outcomes}

Other objective measures of physical activity as secondary outcomes were: 
- sedentary time (measured in minutes per day and percentage of waking hours);

- time spent in light-intensity physical activity (measured in minutes per day and percentage of waking hours);

- walking duration (measured in minutes per day and percentage of waking hours).

These measures can assist in providing a complete picture of physical activity, and include measures of intensity, frequency, and duration (Fini 2015).

We also included self-reported measures of physical activity levels as secondary outcomes, in terms of type of activity and context in which the activity was undertaken.

Additional secondary outcomes included:

- fatigue (e.g. Fatigue Assessment Scale and Fatigue Severity Scale);

- mood (e.g. Hospital Anxiety and Depression Scale, General Health Questionnaire-12 Item, Brief Assessment Schedule Depression Cards, Patient Health Questionnaire-9 item);

- quality of life (QoL; e.g. Stroke Specific Quality of Life Scale, Stroke Impact Scale-16, EuroQol);

- community participation (e.g. World Health Organization (WHO) Disability Assessment Schedule);

- adverse events, such as falls, hospitalisations, and death.

Fatigue, mood, QoL, and community participation are altered following stroke, and an increase in physical activity may have a positive impact on these factors (Hackett 2005; Graven 2011; Duncan 2015).

\section{Search methods for identification of studies}

See the 'Specialized register' section in the Cochrane Stroke Group module. We searched for trials in all languages and planned to arrange for translation of relevant articles where necessary.

\section{Electronic searches}

We searched the following databases:

- Cochrane Stroke Group Trials Register (last searched 3 March 2018);

- Cochrane Central Register of Controlled Trials (CENTRAL; 2018, Issue 2) in the Cochrane Library (last searched 3 March 2018; Appendix 1);

- MEDLINE Ovid (1946 to 3 March 2018; Appendix 2);

- Embase Ovid (1980 to 3 March 2018; Appendix 3)
- CINAHL EBSCO (Cumulative Index to Nursing and Allied Health Literature; 1982 to 3 March 2018; Appendix 4);

- SPORTDiscus EBSCO (1949 to 3 March 2018; Appendix 5).

We developed the MEDLINE search strategy with the help of the Cochrane Stroke Group Information Specialist, and adapted it for the other databases (Appendix 2). We placed no search limitations on language or type of publication.

In addition, we searched the following trial registers, using identical search terms (Appendix 6):

- WHO International Clinical Trials Registry Platform (www.who.int/ictrp/en/; searched 3 March 2018);

- Clinicaltrials.gov (www.clinicaltrials.gov; searched 3 March 2018);

- EU Clinical Trial Register (www.clinicaltrialsregister.eu; searched 3 March 2018);

- ISRCTN Registry (www.isrctn.com; searched 3 March 2018);

- Australian and New Zealand Clinical Trial Registry (www.anzctr.org.au; searched 3 March 2018);

- Stroke Trials Registry (www.strokecenter.org/trials; searched 3 March 2018)

\section{Searching other resources}

To identify any further published, unpublished, or ongoing trials, we:

- searched the reference lists of relevant articles, and used the Web of Science Cited Reference Search for forward tracking of references;

- searched Google Scholar (scholar.google.com), using the terms stroke AND (activity monitor or pedometer or accelerometer); we reviewed the first 200 results; and

- attempted to contact trial authors to obtain further data where required.

\section{Data collection and analysis}

\section{Selection of studies}

All review authors independently screened titles and abstracts of the references obtained from the database searches and other searching activities, and excluded obviously irrelevant reports. For the remaining references, we retrieved full-text articles, which at least two review authors (LJ, NF, MC, DS, HJ, EL, TJ) independently screened to determine eligibility, and noted reasons for exclusion. The two review authors resolved disagreements through discussion, and consulted with a third review author as required. We recorded the selection process and presented it in a PRISMA flow diagram (Figure 1). 
Figure 1. PRISMA flow diagram

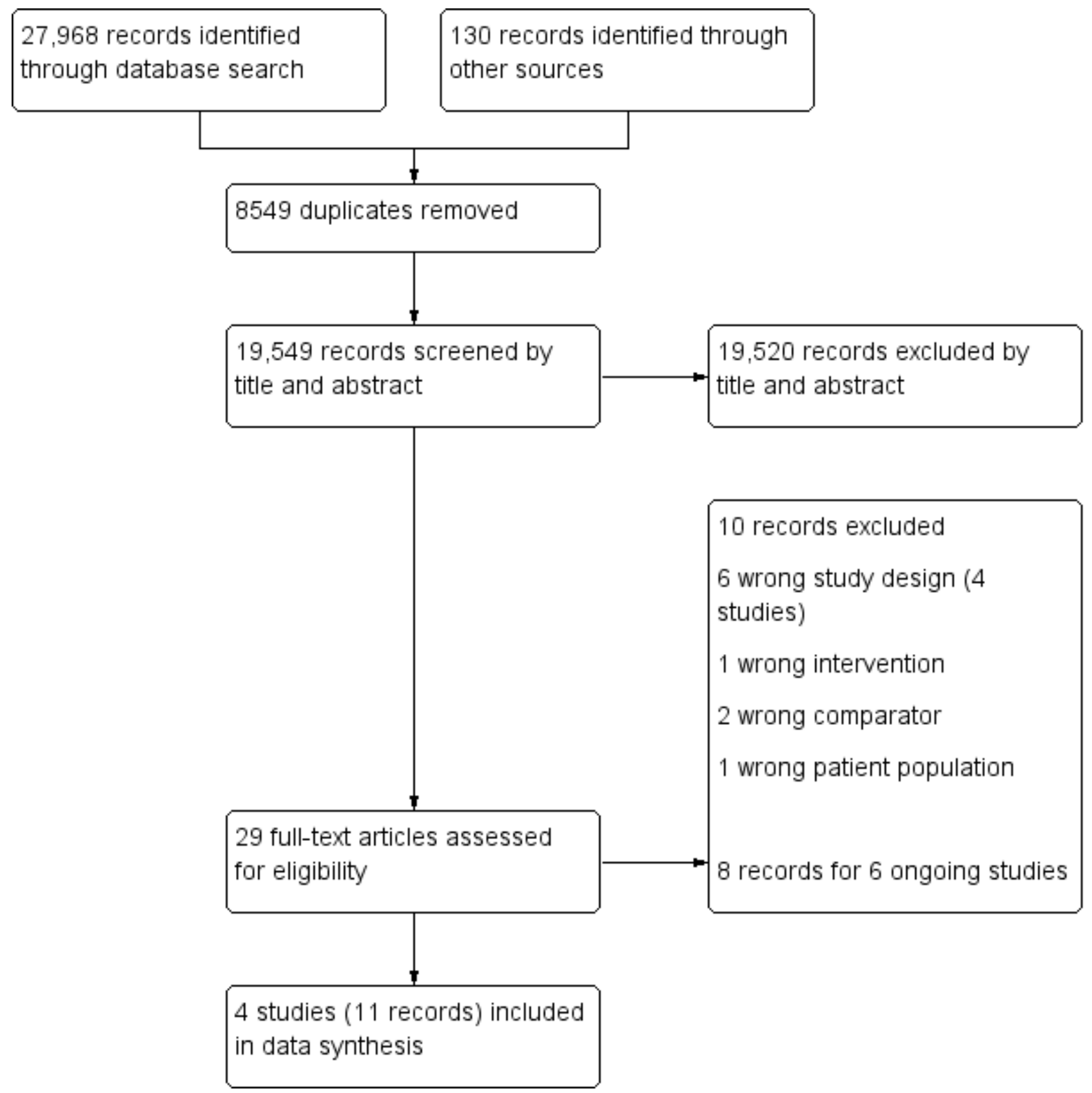

\section{Data extraction and management}

Review authors (TJ, KB, SKr, EL) independently extracted data from included studies and recorded information on a data extraction template in Covidence, developed specifically for this study. We extracted the following data: type of study, participant population, study setting, details of interventions and co-interventions, time frame, and details of outcomes and their definitions. We used headings from the TIDieR checklist to guide the extraction of data about the interventions and co-interventions (Hoffmann 2014). We compared the extracted data and resolved any discrepancies by discussion; EL checked as required.

\section{Assessment of risk of bias in included studies}

Review authors (TJ, SKr, LJ, EL) independently assessed risk of bias for each study using the criteria outlined in the Cochrane Handbook for Systematic Reviews of Interventions (Higgins 2011). The two review authors resolved disagreements by discussion, or by consulting with a third review author (EL). We assessed the risk of bias according to the following criteria:

- Random sequence generation;

- Allocation concealment;

- Blinding of participants and personnel;

- Blinding of outcome assessment;

- Incomplete outcome data; 
- Selective outcome reporting;

- Other bias (e.g. carryover bias in cross-over trials, contamination between groups).

We graded the risk of bias for each domain as high, low, or unclear. A grading of low risk of bias indicated that the study appeared to be free from bias for the domain. We graded a criterion as having an unclear risk of bias when there was insufficient information available to determine whether an important risk of bias was present, or there was a lack of clarity whether an identified problem introduced bias. When there was at least one important risk of bias for a domain, we identified the domain as having a high risk of bias: Figure 2 and Figure 3 presents risks of bias of the included studies.

\section{Figure 2. Risk of bias graph: review authors' judgements about each risk of bias item presented as percentages across all included studies}

\section{Random sequence generation (selection bias) \\ Allocation concealment (selection bias)}

Blinding of participants and personnel (performance bias)

Blinding of outcome assessment (detection bias)

Incomplete outcome data (attrition bias)

Selective reporting (reporting bias)

Other bias

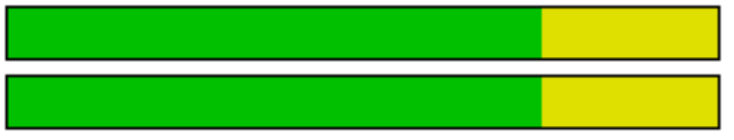

L

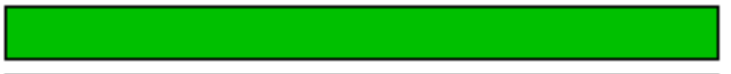

L

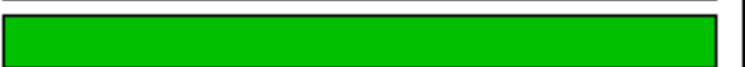

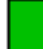

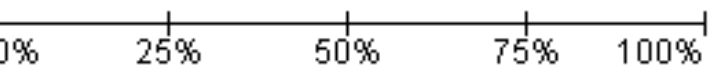


Figure 3. Risk of bias summary: review authors' judgements about each risk of bias item for each included study

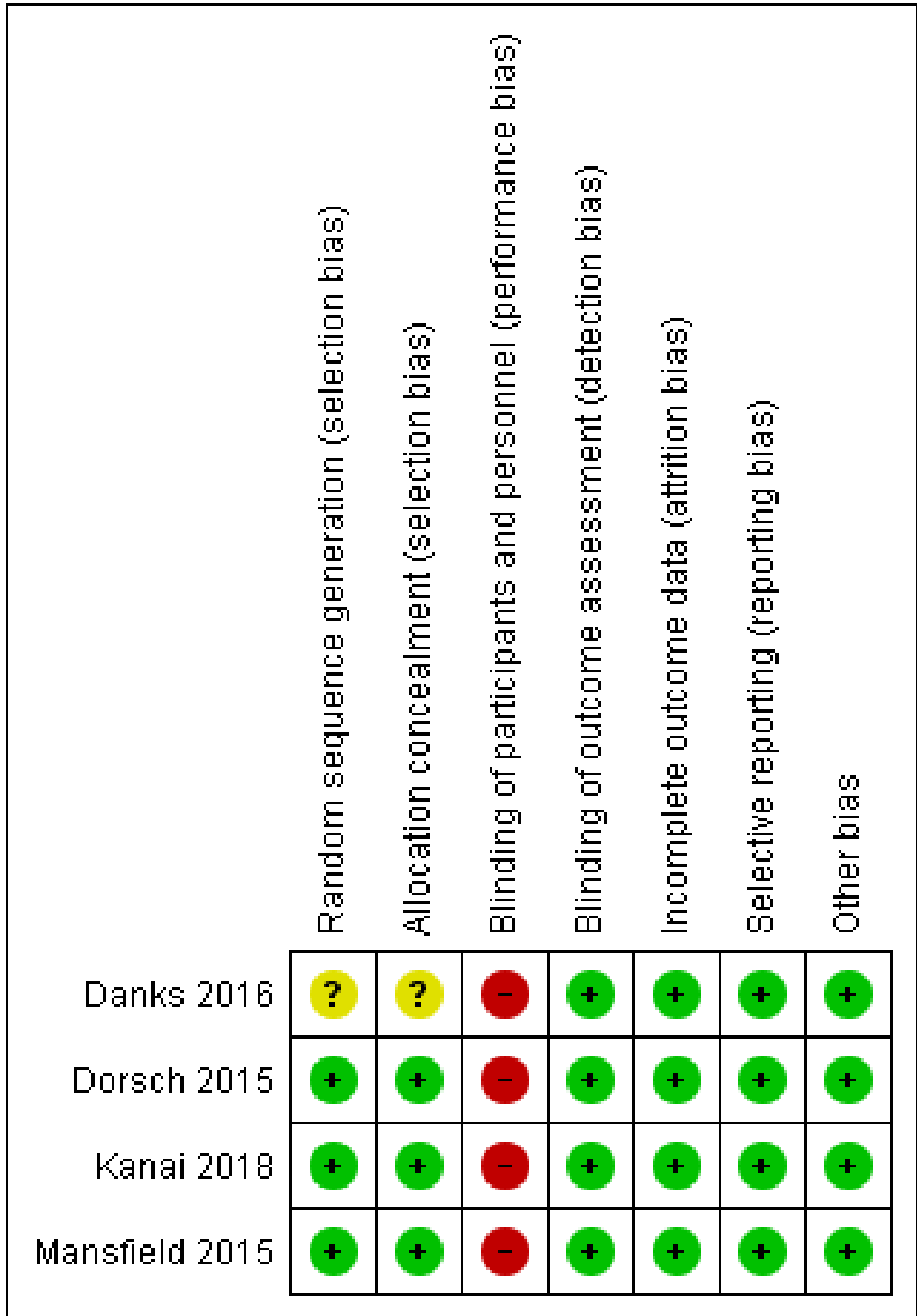

\section{Measures of treatment effect}

We expressed continuous data as mean differences (MDs) with $95 \%$ confidence intervals (Cls) for data measured in the same way between trials, or as standardised mean differences (SMDs) with $95 \%$ Cls to combine data when different scales were used to measure the same concept. We expressed dichotomous data as risk ratios (RRs) with $95 \% \mathrm{Cl}$.

\section{Unit of analysis issues}

We only identified individually randomised trials for this review, so we did not need to analyse for unit of analysis issues, as planned in our protocol (Lynch 2017).

\section{Dealing with missing data}

We followed the methods for sensitivity analysis described in the Cochrane Handbook for Systematic Reviews of Interventions for dealing with missing data (Higgins 2011). We assessed and reported dropout rates for each study, and we used the principle of intentionto-treat analyses (analysis of all participant data according to group allocation). We considered the amount of missing data when determining risk of bias within included studies.

\section{Assessment of heterogeneity}

We visually inspected the forest plots for any evidence of heterogeneity and used the $\mathrm{I}^{2}$ statistic to measure heterogeneity for the one outcome for which we conducted a meta-analysis (steps per day). An $\mathrm{I}^{2}$ statistic of $50 \%$ or higher indicated moderate to substantial heterogeneity. 


\section{Assessment of reporting biases}

We had intended to use funnel plots to assess reporting bias, but we were unable to conduct an assessment of reporting biases (such as publication bias) due to the small number of included studies.

\section{Data synthesis}

We had planned that when there were two or more studies that were similar in terms of participant population and intervention received, we would conduct a meta-analysis by pooling the appropriate data using Review Manager 5 (RevMan 2014). We decided not to pool data from different settings (inpatient setting versus community setting). Given that only two studies collected the same outcome measure with similar participants, only data regarding steps per day (in hospital setting) could be pooled. We described the rest of the findings narratively.

\section{Subgroup analysis and investigation of heterogeneity}

We did not perform the planned additional subgroup analysis (listed below) due to a lack of available data.

\section{- Setting (hospital or community)}

- Type of activity monitor (similar pedometer versus more complex body worn activity monitor)

- Frequency of feedback (real time versus provided at regular intervals)

- Participant-specific factors (to facilitate identification of people with stroke most likely to respond to activity monitor interventions):

* age 18 to 64 years, 65 years and over;

* walking ability (independent or requiring assistance);

* time since stroke (within one month, between one and six months, more than six months);

* gait speed;

* gait endurance.

\section{Sensitivity analysis}

We judged the strength of each study's methods using Cochrane's tool for assessing risk of bias (Higgins 2011). We had planned to perform sensitivity analyses to assess the robustness of the findings by excluding studies from the analysis that were at high risk of bias (Lynch 2017). However, we did not perform our planned sensitivity analyses because we were only able to pool data on one outcome measure from two studies.

\section{GRADE assessment and 'Summary of findings' table}

We presented the main results of the review in Summary of findings tables: Summary of findings for the main comparison, which includes outcomes for community dwelling stroke survivors, and Summary of findings 2, which includes outcomes for participants undergoing inpatient rehabilitation. The tables are for the comparison of activity monitor plus another intervention versus other intervention alone for the primary outcomes of steps per day and time spent in moderate and vigorous physical activity, and the secondary outcomes of sedentary time, time spent in light physical activity and walking duration (rather than the other six secondary outcomes) because these align closely with the definition of physical activity. Two review authors (KB and SKr) independently rated the quality of the evidence provided by the studies that contributed data to the meta-analyses for each outcome using the
GRADE approach (www.gradeworkinggroup.org/) and GRADEpro GTD software (GRADEpro GDT 2015). The footnotes and comments sections contain the justification for all decisions to downgrade or upgrade the quality of studies.

\section{RES U L T S}

\section{Description of studies}

See: Characteristics of included studies; Characteristics of excluded studies; Characteristics of ongoing studies

\section{Results of the search}

We identified a total of 28,098 references from our searching activities, and removed 8549 duplicates. We screened the titles and abstracts of the remaining 19,549 references and excluded 19,520 references. We retrieved 29 articles in full, excluded 10 references, and identified six ongoing studies (eight references). We included four studies (11 articles, 245 participants) in the review (Figure 1).

\section{Included studies}

The four included trials involving 245 participants, were published between 2015 and 2018 in Canada (Mansfield 2015), the USA (Dorsch 2015; Danks 2016), and Japan (Kanai 2018). Sample sizes ranged from 27 (13 and 14 in each group; Danks 2016), to 135 (63 and 72 in each group; Dorsch 2015). The median age of participants ranged from 58 (Danks 2016), to 66 years (Dorsch 2015). Time poststroke varied between studies: Kanai 2018 recruited participants within one week of admission to hospital after stroke; Dorsch 2015 and Mansfield 2015 investigated participants between one to three months poststroke, whereas the participants in Danks 2016 were in the chronic phase poststroke (median 51 months). Studies were conducted in inpatient (acute hospital or rehabilitation) settings (Dorsch 2015; Mansfield 2015; Kanai 2018), and a university-based laboratory (Danks 2016). Stroke severity scores ranged from a median of one (Mansfield 2015; Kanai 2018), to six (Dorsch 2015), on the National Institutes of Health Stroke Scale (NIHSS) and was not reported in Danks 2016. We contacted the authors of Danks 2016 for this information, but did not receive a reply.

\section{Participants}

Participants in each of the studies needed to be able to communicate with investigators (Mansfield 2015; Danks 2016), follow two-stage commands (Dorsch 2015), or not have a diagnosis of dementia or aphasia (Kanai 2018). All participants were able to ambulate to varying degrees: in the study by Dorsch 2015, participants needed to be able to walk five steps within 10 days of rehabilitation admission; and in the studies by Mansfield 2015, Danks 2016, and Kanai 2018, participants needed to be able to walk without supervision or assistance (and without an aid in Kanai 2018).

\section{Interventions}

The interventions all involved the use of activity monitors and provision of feedback on physical activity. Activity monitors used were triaxial accelerometers (Gulf Coast Data Concepts) worn with one sensor on each ankle (Dorsch 2015), one sensor on each limb (Mansfield 2015), Fitbit One (Kanai 2018), and the StepWatch activity monitor (Danks 2016). In Danks 2016, the intervention was fast-walking training plus using the StepWatch activity monitor to 
measure step counts versus fast-walking training alone. The fastwalking training consisted of 20 minutes on a treadmill in a harness followed by 10 minutes of overground walking, aiming to walk at a target heart rate. The aim of the step-activity monitoring was to increase the daily step count by $8 \%$ if the step count was less than 5000 steps per day, $5 \%$ if between 5001 and 7499 steps per day, or $3 \%$ if between 7500 to 9999 steps per day. The intervention in Dorsch 2015 was feedback on speed of walking versus feedback on speed of walking plus daily feedback from the physiotherapist regarding step count, the average and maximum walking speed, and the distance walked. The intervention in Mansfield 2015 consisted of one hour per day of physiotherapy with goal setting versus one hour per day of physiotherapy with goal setting and daily feedback on walking activity. The intervention in Kanai 2018 consisted of goal setting and feedback on steps per day in addition to supervised occupational therapy and physical therapy versus supervised occupational therapy and physical therapy only. The duration of the interventions were three times per week over 12 weeks in Danks 2016, during the inpatient rehabilitation stay (mean 11 to 12 days in Kanai 2018, or median 22 days in Dorsch 2015), and during the inpatient rehabilitation stay, starting when participants met eligibility criteria (median 14 days) in Mansfield 2015.

\section{Outcomes}

Many different outcomes were measured: steps per day (Mansfield 2015; Danks 2016; Kanai 2018), time spent in light, moderate, and vigorous physical activity (Kanai 2018), total time spent walking (Danks 2016), Stroke Impact Scale-16 (SIS-16; Dorsch 2015), selfselected walking speed (Mansfield 2015; Danks 2016), 6-Minute Walk Test (Danks 2016), maximal walking speed over 10 metres (Danks 2016), 3-Minute Walk Test (Dorsch 2015), 15-metre walking speed (Dorsch 2015), time spent in two minutes or more walking bouts (Dorsch 2015), number of walking bouts of more than five minutes duration (Mansfield 2015), longest bout duration (Mansfield 2015), energy expenditure (Kanai 2018), Functional Ambulation Category (Dorsch 2015), average cadence, step-length symmetry, swing-time symmetry, step-length variability, steptime variability, step-width variability (Mansfield 2015), stroke self-efficacy score (Mansfield 2015), and self-efficacy for physical activity score (Kanai 2018). Dorsch 2015 collected data on walking time per day over the course of the trial, rather than at the end of the intervention. The study authors did not respond to emailed queries regarding availability of end-of-intervention data, so these data were not included in the analysis. Table 1 presents the outcomes reported in the included studies mapped to the outcomes of interest for this review (Lynch 2017).

\section{Excluded studies}

We excluded the 10 publications for a variety of reasons, including wrong study design and wrong comparator. See Characteristics of excluded studies for individual reasons for exclusions.

\section{Ongoing studies}

We identified six ongoing studies in eight publications. See Characteristics of ongoing studies.

\section{Risk of bias in included studies}

Figure 2 summarises the trials, together with risk of bias in the seven domains. The most prevalent risk of bias was in the area of performance bias, which was always rated as high risk due to the inability to blind therapists and participants. Figure 3 shows the risk of bias in each of the included trials individually.

\section{Allocation}

In one of the four studies, the generation technique of the random sequence and details regarding allocation concealment were not reported (Danks 2016). Authors did not respond to emailed queries regarding them, so we deemed this study's risk of selection bias to be unclear. The remaining three studies adequately described the randomisation technique and concealed allocation process, and we deemed the risk of selection bias for these studies to be low.

\section{Blinding}

Blinding was not possible for personnel (therapists) in any of the studies, and was either not possible or unclear for participants, so we judged the risk of performance bias to be high in all included studies. All studies reported blinding of outcome assessment except Kanai 2018, where data for three of the four outcome measures were downloaded from the accelerometer, and selfefficacy was collected by physiotherapists who were not blinded to participants' group allocation. We judged all studies to have a low risk of detection bias.

\section{Incomplete outcome data}

There was some participant attrition in all four included studies. However, all participants were accounted for in all papers, with reasons for attrition clearly provided. The proportion of participants with complete outcome data was greater than $80 \%$ in all papers. Therefore, we deemed the risk of bias due to incomplete outcome data to be low.

\section{Selective reporting}

Two of the four included studies published study protocols (Dorsch 2015; Mansfield 2015), whilst all papers published all predefined study outcomes. Therefore, we judged all four included papers to have a low risk of reporting bias.

\section{Other potential sources of bias}

We did not identify any other potential sources of bias.

\section{Effects of interventions}

See: Summary of findings for the main comparison Activity monitor plus other intervention compared to other intervention alone for increasing physical activity in adult community dwelling stroke survivors; Summary of findings 2 Activity monitor plus other intervention compared to other intervention alone for increasing physical activity in adult stroke survivors during inpatient rehabilitation

See Summary of findings for the main comparison (community dwelling stroke survivors) and Summary of findings 2 (stroke survivors participating in inpatient rehabilitation) for the main comparison of activity monitor plus another intervention versus other intervention alone for increasing physical activity in adult stroke survivors. The summary of findings tables present our primary outcome measures and secondary outcomes that align with physical activity (i.e. sedentary time, time spent in light intensity physical activity and walking duration). None of the included studies reported or measured our primary outcome measure of time spent in MVPA or our secondary outcome measures 
of sedentary time, self-reported physical activity, fatigue, mood, community participation, adverse events, or death.

\section{Primary outcomes}

\section{Steps per day}

Three studies (110 participants) measured physical activity using steps per day (Mansfield 2015; Danks 2016; Kanai 2018). The participant populations were different between the three studies (one study included people living in community, and two studies included people participating in inpatient rehabilitation). There was no significant difference in steps per day between groups for the study conducted in a community setting by Danks 2016 (MD $-1.93,95 \% \mathrm{Cl}-4.41$ to $0.55 ; 27$ participants). Using the GRADE criteria, we assessed the quality of evidence for the outcome steps per day in community dwelling stroke survivors as very low due to the lack of blinding of participants and personnel and the small sample size. As presented in Analysis 1.1, when we pooled data collected from people participating in inpatient rehabilitation, there was no significant difference in steps per day between groups (mean difference (MD) 1.40 steps (x1000), 95\% confidence intervals (CI) -0.04 to 2.84; two RCTs, 83 participants). The $\mathrm{I}^{2}$ statistic was $65 \%$, indicating substantial heterogeneity between these two studies. We assessed the quality of evidence for the outcome steps per day in inpatient rehabilitation as very low using GRADE criteria based on the lack of blinding, lack of information regarding the randomisation procedure, the small sample size and heterogeneity.

\section{Time spent in moderate-to-vigorous intensity physical activity (MVPA)}

No studies reported time in MVPA. One study (48 participants participating in inpatient rehabilitation) presented data separately for moderate-intensity and vigorous-intensity activity (Kanai 2018). At the end of the intervention period, time in moderate-intensity activity was significantly higher in the activity monitor group compared with usual rehabilitation (MD $4.40,95 \% \mathrm{Cl} 0.28$ to 8.52 ), but time in vigorous-intensity activity was not significantly different between groups (MD 2.60, 95\% Cl-0.80 to 6.00). Regardless of group allocation, the time spent in moderate-intensity activity was very low (2.7 minutes per day versus 7.1 minutes per day). Analysis 1.2 presents data regarding time in moderate, vigorous and light physical activity, the evidence for these outcomes was low as it was based on a small study in which personnel and participants were not blinded.

\section{Secondary outcomes}

\section{Sedentary time}

None of the four included studies reported measures of sedentary time.

\section{Time spent in light intensity physical activity}

One study (48 participants) reported time spent in light-intensity physical activity (Kanai 2018) during inpatient rehabilitation. At the end of the intervention period, time in light-intensity physical activity was significantly higher in the group assigned to use activity monitors (MD 25.80 minutes, $95 \% \mathrm{Cl} 0.48$ to 51.12 ), as illustrated in Analysis 1.2. We rated the quality of evidence as low using GRADE criteria due to the small number and lack of blinding of participants.

\section{Walking duration}

Two studies (62 participants) measured total walking time at the end of the intervention period (Mansfield 2015; Danks 2016). The participant populations were different between the two studies (people in inpatient rehabilitation and people living in the community) so we did not pool the data, but presented them separately in Analysis 1.3. There was no significant difference in total walking time between groups in either study. We rated the quality of evidence for inpatient rehabilitation and community dwelling stroke survivor studies as low using the GRADE criteria due to the small number and lack of blinding of participants.

\section{Fatigue}

None of the four included studies reported measures of fatigue.

\section{Mood}

None of the four included studies reported measures of mood.

\section{Quality of life (QoL)}

One study (135 participants) measured QoL using the SIS-16 (Dorsch 2015). At the end of the intervention period, QoL was not significantly different between groups. We rated the quality of evidence as low, because participants and personnel were not blinded, and the confidence interval was wide, spanning both a positive effect as well as a negative effect of the intervention.

\section{Community participation}

None of the four included studies reported measures of community participation

\section{Adverse events}

None of the four included studies reported measures of adverse events such as falls, hospitalisations, or death.

\section{DISCUSSION}

\section{Summary of main results}

The primary aim of this review was to determine if activity monitors were effective in increasing physical activity levels of people with stroke. There is very low-qualityevidence that interventions that used activity monitors in conjunction with another intervention may not have an effect on step counts for community dwelling stroke survivors or during inpatient rehabilitation. None of the studies reported time spent on MVPA.

One study explored the effect of fast-walking training with stepactivity monitoring on daily step count and measures of walking ability (Danks 2016). Another study reported on the effect of feedback on walking speed and walking activity on time spent walking per day and walking ability (Dorsch 2015). Two studies reported on the effect of daily feedback on physical activity in addition to usual inpatient rehabilitation on daily step counts, along with other measures of mobility and activity (Mansfield 2015; Kanai 2018). Three of the four studies reported on our primary outcome measure of step count at the end of the intervention, and only one study reported on our primary outcome measure of time spent in moderate-intensity activity. Overall, we observed no significant effect for interventions that used activity monitors in conjunction with another intervention on step counts in people with stroke (mean difference (MD) in inpatient setting 1400 more 
steps, $95 \% \mathrm{Cl}-40$ to 2840 ; MD in community setting: 1930 fewer steps, $95 \% \mathrm{Cl}-4410$ to 550 ). One small study showed that use of activity monitors had a significant effect on time spent in moderateintensity physical activity but no significant effect on time spent in vigorous-intensity physical activity for people in inpatient settings (MD in time spent in moderate-intensity activity in inpatient setting 4.4 minutes longer, $95 \% \mathrm{Cl} 0.28$ to 8.52 ; $\mathrm{MD}$ in time spent in vigorous-intensity activity in inpatient setting 2.6 minutes longer, $95 \% \mathrm{Cl}-0.8$ to 6$)$.

\section{Overall completeness and applicability of evidence}

Research regarding the use of wearable activity monitors is in its infancy, but with six ongoing studies identified, the momentum of this field of research is growing. We included four small RCTs that were conducted in different settings (inpatient rehabilitation and community) with people of different walking abilities. Three of the four included studies used research-grade activity monitors (StepWatch activity monitor and Gulf Coast Data Concepts triaxial accelerometer); only one study used an activity monitor designed for use by consumers (Fitbit One) in the interventions. No consistent outcome measure was used in all four studies, which limited our ability to pool the available data. Therefore, our ability to reach generalisable conclusions relating to the effect of activity monitors to improve physical activity in people with stroke was limited. The issue of a lack of commonality in outcome measures in stroke rehabilitation research has been noted previously, leading to the development, by a group of international stroke research experts, of consensus-based core recommendations to measure sensorimotor recovery in future stroke rehabilitation trials (Kwakkel 2017).

Overall, the four included studies did not find a beneficial effect from the addition of activity monitors to other interventions on most of our outcomes, with the exception of light- and moderateintensity physical activity, which were measured in only one study. It is important to consider that there are many factors that contribute to reduced activity levels after stroke, such as physical disability, fear of falling, a lack of understanding about what activity is allowed or safe after stroke, and sedentary lifestyle habits (Nicholson 2013; English 2016b). Activity monitors are likely to be most effective in changing activity levels when they are incorporated as a tool in a multifaceted behaviour change intervention, which address pertinent factors that inhibit activity levels.

\section{Quality of the evidence}

Overall, the quality of the evidence was low to very low according to GRADE criteria, due to the small number of trials and sample sizes included in the review, which led to confidence intervals for six of the eight included outcomes reporting both positive and negative effects of the activity monitor intervention, and the high risk of performance and detection bias in the included studies.

There was very low-quality evidence for the number of steps per day in inpatient settings, time spent in vigorous-intensity physical activity, and total time spent walking in inpatient rehabilitation and community settings.The true effect may be substantially different from the estimate of effect.

There was very low-quality evidence for steps per day in community settings. We have very little confidence in this effect estimate, the true effect is likely to be substantially different from the estimate of effect.

There was low-quality evidence for time spent in low,- moderateand vigorous intensity physical activity. We have limited confidence in the effect, the true effect may be substantially different from the estimate of the effect.

\section{Potential biases in the review process}

While our literature search was extensive, there remains a risk of selection bias. We attempted to reduce potential bias by having two review authors screen studies for inclusion eligibility, and we resolved discrepancies in collaboration with a third review author if the original two review authors could not achieve consensus. Two review authors independently extracted data and assessed risk of bias of the included studies, with discrepancies resolved by consensus or with another review author. However, subjective judgements were required during the review process, and a different review team may judge risk of bias differently.

\section{Agreements and disagreements with other studies or reviews}

The findings from this review are different from previous reports in other populations regarding the effectiveness of activity monitors to increase physical activity. Activity monitors and mobile applications have been used to increase physical activity in healthy adults (Kirwan 2012; Finkelstein 2016), hospitalised adults undergoing cardiac rehabilitation (Izawa 2012), and overweight adults (de Vries 2016), with good effect. However, often these are used in combination with a behaviour change intervention (Izawa 2012; de Vries 2016), or online programmes that provide information and support to increase physical activity (Kirwan 2012).

Activity monitor or mobile application interventions that do not specifically target physical activity goals (e.g. those that target weight loss, but also measure physical activity) do not lead to increases in physical activity (Mateo 2015). Activity monitor or mobile application interventions that do not incorporate behaviour change strategies, provide additional information or support to increase physical activity, or specifically target physical activity goals, have not demonstrated effectiveness in increasing physical activity levels (Mateo 2015; Finkelstein 2016). In contrast, behaviour change interventions have demonstrated good potential in increasing physical activity in people with stroke (Jones 2015).

Therefore, it is likely that the lack of consistent effectiveness of physical activity monitors for increasing physical activity in the included articles in this review can be explained, at least in part, by the lack of incorporation of specific behaviour change strategies. One of the most widely used frameworks for understanding and changing behaviour is the COM-B (capability, opportunity, motivation and behaviour) framework and the associated Behaviour Change Wheel (Michie 2011; Michie 2014). The premise of COM-B is that behaviour is determined by capability, opportunity, and motivation, so in order to change behaviour, a person's capability, opportunity, and motivation to perform that behaviour need to be addressed. In terms of physical activity after stroke, a person's capability to be physically active might be limited due to physical barriers, such as weakness, pain, reduced balance, or fatigue. Physical capability is typically the focus of physiotherapy 
interventions; the interventions received by both the treatment and control groups in all four studies included in this review targeted physical capability by addressing mobility and independence. Psychological capability encompasses factors such as knowing why activity is important, and what sort of activities constitute 'physical activity'. Opportunity includes a safe environment in which to be active, including the provision of assistance when required, and support from others, such as peers, health professionals, and family members to be active. Motivation includes both the desire to perform physical activity, as well as developing plans and habits of being active. While the use of activity monitors facilitated feedback of current performance, this feedback was not specifically embedded within a programme that addressed all of the factors influencing behaviour, mentioned above, in most of the included studies. The most recent study, which incorporated access to real time feedback (via a device designed for consumer use) and daily goal-setting with physiotherapists as part of the intervention, reported the most positive results (Kanai 2018). We hypothesise that incorporating the use of activity monitors as a tool within a multifaceted behaviour change intervention may prove to be more effective in changing physical activity levels in future studies.

\section{AUTHORS' CONCLUSIONS}

\section{Implications for practice}

The current evidence is insufficient to make a recommendation about the use of activity monitors for stroke survivors to increase physical activity in inpatient or community settings. The limited low to very low quality evidence currently available indicated that adding the use of activity monitors to general rehabilitation programmes did not appear to be an effective strategy to increase physical activity levels, in terms of step counts or levels of MVPA in people with stroke.

\section{Implications for research}

More research investigating the use of activity monitors is required. Given the complexity of changing physical activity levels, further research is warranted to investigate whether activity monitors provide added value to structured behaviour modification programmes aimed at increasing physical activity. No outcome measure was used in all four included studies, so we recommend that researchers use consistent outcome measures, as recommended by Kwakkel 2017, so that data can be compared and pooled across studies. As recommended by Walker 2017, usual rehabilitation care should be clearly described to allow comparisons between studies.

\section{ACKNOWLEDGEMENTS}

We thank the Cochrane Stroke Group Editorial Team (special thanks to Hazel Fraser and Josh Cheyne) for assisting us with the development of this protocol. Thank you to Catherine Marshall for helpful comments in the review phase. We also thank Debbie Booth for assistance with the trials register and Google Scholar search.

E Lynch was supported by National Health and Medical Research Council (NHMRC) Centre for Research Excellence in Stroke Rehabilitation and Brain Recovery (1077898) and an NHMRC Early Career Fellowship (1138515).

The Florey Institute acknowledges Victorian Government support, particularly the Operational Infrastructure Support Grant. 


\section{RE F E R E N C E S}

\section{References to studies included in this review}

Danks 2016 \{published data only\}

* Danks KA, Pohlig R, Reisman DS. Combining fast-walking training and a step-activity monitoring program to improve daily walking activity after stroke: a preliminary study. Archives of Physical Medicine and Rehabilitation 2016;97(9 Suppl):S185-93.

Danks KA, Roos MA, McCoy D, Reisman DS. A step-activity monitoring program improves real world walking activity post stroke. Disability and Rehabilitation 2014;36(26):2233-6.

\section{Dorsch 2015 \{published data only\}}

Dorsch A, Thomas S, Xu C, Kaiser W, Dobkin B. Implementation of a multicenter, international, randomized clinical trial in subacute stroke patients using wireless health technology. Neurorehabilitation and Neural Repair 2014;28(4):NP17.

Dorsch A, Thomas S, Xu C, Kaiser W, Dobkin B. SIRRACT: a multi-center, international, randomized clinical trial using wireless technology to affect outcomes during acute stroke rehabilitation. Neurology 2013; Vol. 80, issue Meeting abstracts.

* Dorsch AK, Thomas S, Xu X, Kaiser W, Dobkin BH. SIRRACT: an international randomized clinical trial of activity feedback during inpatient stroke rehabilitation enabled by wireless sensing. Neurorehabilitation and Neural Repair 2015;29(5):407-15. [DOI: 10.1177/1545968314550369]

NCT01246882. Stroke Inpatient Rehabilitation Reinforcement of ACTivity (SIRRACT). clinicaltrials.gov/ct2/show/NCT01246882 (first received 22 November 2010).

\section{Kanai 2018 \{published data only\}}

Kanai M, Izawa KP, Kobayashi M, Onishi A, Kubo H, Nozoe M, et al. Effect of accelerometer-based feedback on physical activity in hospitalized patients with ischemic stroke: a randomized controlled trial. Clinical Rehabilitation 2018;Feb 1 [epub ahead of print]:269215518755841. [DOI: 10.1177/0269215518755841]

\section{Mansfield 2015 \{published data only\}}

Mansfield A, Wong J, Inness E. Does accelerometer-based feedback increase walking activity during inpatient rehabilitation post-stroke? Preliminary results from a randomized controlled trial. Neurorehabilitation and Neural Repair 2014;28(4):NP19.

Mansfield A, Wong JS, Bayley M, Biasin L, Brooks D, Brunton K, et al. Using wireless technology in clinical practice: does feedback of daily walking activity improve walking outcomes of individuals receiving rehabilitation post-stroke? Study protocol for a randomized controlled trial. BMC Neurology 2013;13(1):93.

* Mansfield A, Wong JS, Bryce J, Brunton K, Inness EL, Knorr S, et al. Use of accelerometer-based feedback of walking activity for appraising progress with walking-related goals in inpatient stroke rehabilitation: a randomized controlled trial. Neurorehabilitation and Neural Repair 2015;29(9):847-57.
NCT01521234. Using wireless-technology for feedback of daily walking activity post-stroke. clinicaltrials.gov/ct2/show/ NCT01521234 (first received 23 January 2012).

\section{References to studies excluded from this review}

Bird 2016 \{published data only\}

Bird ML, Cannell J, Callisaya M, Moles E, Rathjen A, Lane K, et al. "FIND Technology": investigating the feasibility, efficacy and safety of controller free interactive digital rehabilitation technology in an inpatient stroke population: study protocol for a randomized controlled trial. Trials 2016;17:203.

\section{Gandhi 2017 \{published data only\}}

Gandhi S, Chen S, Hong L, Sun K. Effect of mobile health interventions on the secondary prevention of cardiovascular disease: systematic review and meta-analysis. Canadian Journal of Cardiology 2017;33:219-31.

Koh 2015 \{published data only\}

Koh GC-H, Yen SC, Tay A, Cheong A, Ng YS, De Silva DA et al. Singapore tele-technology aided rehabilitation in stroke (STARS) trial: protocol of a randomized clinical trial on tele-rehabilitation for stroke patients. BMC Neurology 2015;15(1):161. [DOI: 10.1186/s12883-015-0420-3]

\section{Martin 2015 \{published data only\}}

Martin SSI, Feldman DI, Blumenthal RS, Jones SR, Post WS, McKibben RA, et al. mActive: a randomized clinical trial of an automated $\mathrm{mHealth}$ intervention for physical activity promotion. Journal of the American Heart Association 2015;4:e002239.

\section{Pandey 2013 \{published data only\}}

Pandey A, Lushbough C, Truong A, Jensen A, Bretz M, Henasey D, et al. The Mobile Applications for Stroke (MAPPS) Investigators. Availability and efficacy of mobile health technology targeting patients: a systematic evidence-based review. Stroke 2013;44(Suppl 1):Abstract TP408.

\section{Paul 2016 \{published data only\}}

Dybus A, Paul L, Wyke S, Brewster S, Alexander G, Gill J, et al. Increasing physical activity in stroke survivors using STARFISH, an interactive mobile phone application: a feasibility study. Cerebrovascular Diseases 2014;37:299.

* Paul L, Wyke S, Brewster S, Sattar N, Gill JMR, Alexander G, et al. Increasing physical activity in stroke survivors using STARFISH, an interactive mobile phone application: a pilot study. Topics in Stroke Rehabilitation 2016;23(3):170-7.

\section{Sakakibara 2014 \{published data only\}}

Sakakibara BM, Eng JJ, Benavente O, Goldsmith CH, Silverberg ND, Yao J. A telehealth intervention to promote healthy lifestyles after stroke: the stroke coach protocol. Stroke 2014;45(12):e285. 
Seo 2015 \{published data only\}

Seo WK, Kang J, Jeon M, Lee K, Lee S, Kim JH, et al. Feasibility of using a mobile application for the monitoring and management of stroke-associated risk factors. Cerebrovascular Diseases 2014;38:101.

* Seo WK, Kang J, Jeon M, Lee K, Lee S, Kim JH, et al. Feasibility of using a mobile application for the monitoring and management of stroke-associated risk factors. Journal of Clinical Neurology 2015;11(2):142-8.

\section{References to ongoing studies}

ACTRN12616001733460p \{published data only\}

ACTRN12616001733460p. Walking to better health after stroke. www.anzctr.org.au/Trial/Registration/TrialReview.aspx? id=372007 (first submitted 9 December 2016).

\section{Kee 2016 \{published data only\}}

Heron N, Kee F, Mant J, Reilly PM, Cupples M, Tully M, et al. Stroke Prevention Rehabilitation Intervention Trial of Exercise (SPRITE) - a randomised feasibility study. BMC Cardiovascular Disorders 2017;17:290.

* NCT02712385. SPRITE - a feasibility and pilot study (SPRITE). clinicaltrials.gov/ct2/show/NCT02712385 (first submitted 28 February 2016).

\section{Klassen 2015 \{published data only\}}

Klassen TD, Eng JJ, Bayley M, Benavente O, Bennett J, Fraser J, et al. Implementing an extra hour of intensive, task-specific, physical therapy daily for individuals post-stroke during inpatient rehabilitation: feasibility data from the DOSE study. International Journal of Stroke 2015;10:86.

* NCT01915368. Determining Optimal Post-Stroke Exercise (DOSE). clinicaltrials.gov/ct2/show/NCT01915368 (first submitted 11 July 2013).

\section{NCT02494245 \{published data only\}}

NCT02494245. Increasing physical activity in stroke survivors using STARFISH, an interactive mobile phone app. clinicaltrials.gov/ct2/show/NCT02494245 (first submitted 1 July 2015).

\section{NCT02587585 \{published data only\}}

NCT02587585. The effect of activity feedback enabled by smart watches during in-patient stroke rehabilitation. clinicaltrials.gov/ct2/show/NCT02587585 (first submitted 30 September 2015).

\section{NCT02835313 \{published data only\}}

NCT02835313. Promoting Recovery Optimization with WALKing exercise after Stroke (PROWALKS). clinicaltrials.gov/ct2/show/ NCT02835313 (first submitted 11 July 2016).

\section{Additional references}

\section{Billinger 2014}

Billinger SA, Arena R, Bernhardt J, Eng JJ, Franklin BA, Johnson CM, et al. Physical activity and exercise recommendations for stroke survivors: a statement for healthcare professionals from the American Heart Association. Stroke 2014;45:2532-53.

\section{Bort-Roig 2014}

Bort-Roig J, Gilson ND, Puig-Ribera A, Contreras RS, Trost SG. Measuring and influencing physical activity with smartphone technology: a systematic review. Sports Medicine 2014;44:671-86.

\section{Caspersen 1985}

Caspersen CJ, Powell KE, Christenson GM. Physical activity, exercise and physical fitness: definitions and distinctions for health-related research. Public Health Reports 1985;100:26-31.

\section{de Vries 2016}

de Vries HJ, Kooiman TJ, van Ittersum MW, van Brussel M, de Groot M. Do activity monitors increase physical activity in adults with overweight or obesity? A systematic review and meta-analysis. Obesity 2016;24(10):2078-91.

\section{Duncan 2015}

Duncan F, Lewis SJ, Greig CA, Dennis MS, Sharpe M, MacLullich AM, et al. Exploratory longitudinal cohort study of associations of fatigue after stroke. Stroke 2015;46(4):1052-8.

Eng 2007

Eng JJ, Tang PF. Gait training strategies to optimize walking ability in people with stroke: a synthesis of the evidence. Expert Review of Neurotherapeutics 2007;7:1417-36.

\section{English 2014}

English C, Manns PJ, Tucak C, Bernhardt J. Physical activity and sedentary behaviors in people with stroke living in the community: a systematic review. Physical Therapy 2014;94:185-96.

\section{English 2016}

English C, Healy GN, Coates A, Lewis L, Olds T, Bernhardt J. Sitting and activity time in people with stroke. Physical Activity 2016;96:193-201.

\section{English 2016b}

English C, Healy GN, Coates A, Lewis LK, Olds T, Bernhardt J. Sitting time and physical activity after stroke: physical ability is only part of the story. Topics in Stroke Rehabilitation 2016;23(1):36-42.

\section{Fanning 2012}

Fanning J, Mullen SP, McAuley E. Increasing physical activity with mobile devices: a meta-analysis. Journal of Medical Internet Research 2012;14:e161.

\section{Feigin 2014}

Feigin VL, Forouzanfar MH, Krisnhamurthi R, Mensah GA, Connor M, Bennett DA, Global Burden of Diseases, Injuries and 
Risk Factors Study 2010 (GBD 2010) and the GBD Stroke Experts Group. Global and regional burden of stroke during 1990-2010: findings from the Global Burden of Disease Study 2010. Lancet 2014;383:245-55.

\section{Feigin 2016}

Feigin VL, Roth GA, Naghavi M, Parmar P, Krishnamurthi R, Chugh S, Global Burden of Diseases, Injuries and Risk Factors Study 2013 and Stroke Experts Writing Group. Global burden of stroke and risk factors in 188 countries, during 1990-2013: a systematic analysis for the Global Burden of Disease Study 2013. Lancet Neurology 2016;15:913-24.

\section{Fini 2015}

Fini NA, Holland AE, Keating J, Simek J, Bernhardt J. How is physical activity monitored in people following stroke? Disability and Rehabilitation 2015;37(19):1717-31.

\section{Fini 2017}

Fini NA, Holland AE, Keating J, Simek J, Bernhardt J. How physically active are people following stroke? Systematic review and quantitative synthesis. Physical Therapy 2017;97(7):707-17.

\section{Finkelstein 2016}

Finkelstein EA, Haaland BA, Bilger M, Sahasranaman A, Sloan RA, Nang EEK, et al. Effectiveness of activity trackers with and without incentives to increase physical activity (TRIPPA): a randomised controlled trial. The Lancet Diabetes and Endocrinology 2016;4(12):983-95.

\section{Freedson 1998}

Freedson PS, Melanson E, Sirard J. Calibration of the Computer Science and Applications, Inc. accelerometer. Medicine and Science in Sports and Exercise 1998;30:777-81.

\section{Glynn 2013}

Glynn LG, Hayes PS, Casey M, Flynn F, Alvarez-Iglesias A, Newell J, et al. SMART MOVE - a smartphone-based intervention to promote physical activity in primary care: study protocol for a randomized controlled trial. Trials 2013;14:157.

\section{GRADEpro GDT 2015 [Computer program]}

GRADE Working Group, McMaster University. GRADEpro GDT. Version (accessed on 18 July 2018). Hamilton (ON): GRADE Working Group, McMaster University, 2015.

\section{Graven 2011}

Graven C, Brock K, Hill K, Joubert L. Are rehabilitation and/or care coordination interventions delivered in the community effective in reducing depression, facilitating participation and improving quality of life after stroke?. Disability and Rehabilitation 2011;33(7/18):1501-20.

\section{Hackett 2005}

Hackett ML, Yapa C, Parag V, Anderson CS. Frequency of depression after stroke: a systematic review of observational studies. Stroke 2005;36:1330-40.

\section{Haskell 2007}

Haskell W, Lee I, Pate RR, Powell KE, Blair SN, Franklin BA, et al. Physical activity and public health: updated recommendation for adults from the American College of Sports Medicine and the American Heart Association. Medicine and Science in Sports and Exercise 2007;39:1423-34.

\section{Healy 2008}

Healy GN, Dunstan DW, Salmon J, Cerin E, Shaw JE, Simmet PZ, et al. Breaks in sedentary time: beneficial associations with metabolic risk. Diabetes Care 2008;31:661-6.

\section{Higgins 2011}

Higgins JPT, Green S, editor(s). Cochrane Handbook for Systematic Reviews of Interventions Version 5.1.0 (updated March 2011). The Cochrane Collaboration, 2011. Available from handbook.cochrane.org.

\section{Higgins 2016}

Higgins JP. Smartphone applications for patients' health and fitness. American Journal of Medicine 2016;129:11-9.

\section{Hoffmann 2014}

Hoffmann TC, Glasziou PP, Boutron I, Milne R, Perera R, Moher D, et al. Better reporting of interventions: Template for Intervention Description and Replication (TIDieR) checklist and guide. BMJ 2014;348:g1687.

\section{Izawa 2012}

Izawa KP, Watanabe S, Hiraki K, Morio Y, Kasahara Y, Takeichi N et al. Determination of the effectiveness of accelerometer use in the promotion of physical activity in cardiac patients: a randomized controlled trial. Archives of Physical Medicine and Rehabilitation 2012;93(11):1896-902.

\section{Jones 2015}

Jones TM, Dean CM, Hush JM, Dear BF, Titov N. A systematic review of the efficacy of self-management programs for increasing physical activity in community-dwelling adults with acquired brain injury. Systematic Reviews 2015;4:51.

\section{Kirwan 2012}

Kirwan M, Duncan MJ, Vandelanotte C, Mummery WK. Using smartphone technology to monitor physical activity in the 10,000 Steps program: a matched case-control trial. Journal of Medical Internet Research 2012;14(2):e55.

\section{Kohl 2012}

Kohl HW, Craig CL, Lambert EV, Inoue S, Alkandari JR, Leetongin G, Lancet Physical Activity Series Working Group. The pandemic of physical inactivity: global action for public health. Lancet 2012;380:294-305.

\section{Kwakkel 2017}

Kwakkel G, Lannin NA, Borschmann K, English C, Ali M, Churilov L, et al. Standardized measurement of sensorimotor recovery in stroke trials: consensus-based core recommendations from the Stroke Recovery and Rehabilitation Roundtable. International Journal of Stroke 2017;12(5):451-61.

\section{Lindgren 2004}

Lindgren M, Unosson M, Fredrikson M, Ek A-C. Immobility - a major risk factor for development of pressure ulcers among 
adult hospitalized patients: a prospective study. Scandinavian Journal of Caring Sciences 2004;18:57-64.

\section{Lord 2004}

Lord SE, McPherson K, McNaughton HK, Rochester L, Weatherall M. Community ambulation after stroke: how important and obtainable is it and what measures appear predictive?. Archives of Physical Medicine and Rehabilitation 2004;85:234-9.

\section{Lynch 2017}

Lynch EA, Borschmann K, Callisaya ML, Fini NA, Janssen H, Johnson L, the ACTIOnS Collaboration. Activity monitors for increasing physical activity in adult stroke survivors. Cochrane Database of Systematic Reviews 2017, Issue 2. [DOI: 10.1002/14651858.CD012543]

\section{Löllgen 2009}

Löllgen H, Bockenhoff A, Knapp G. Physical activity and allcause mortality: an updated meta-analysis with different intensity categories. International Journal of Sports Medicine 2009;30:213-24.

\section{Mateo 2015}

Mateo GF, Granado-Font E, Ferré-Grau C, Montaña-Carreras X. Mobile phone apps to promote weight loss and increase physical activity: a systematic review and meta-analysis. Journal of Medical Internet Research 2015;17(11):e253.

\section{McDonnell 2013}

McDonnell MN, Hillier SL, Hooker SP, Le A, Judd SE, Howard VJ. Physical activity frequency and risk of incident stroke in a national US study of blacks and whites. Stroke 2013;44:2519-24.

\section{Michie 2011}

Michie S, van Stralen MM, West R. The behaviour change wheel: a new method for characterising and designing behaviour change interventions. Implementation Science 2011;6:42.

\section{Michie 2014}

Michie S, Atkins L, West R. The Behaviour Change Wheel. A Guide to Designing Interventions. UK: Silverback Publishing, 2014.

\section{Nakhasi 2014}

Nakhasi A, Shen AX, Passarella RJ, Appel LJ, Anderson CA. Online socials networks that connect users to physical activity partners: a review and descriptive analysis. Journal of Medical Internet Research 2014;16:e153.

\section{Nicholson 2013}

Nicholson S, Sniehotta FF, van Wijck F, Greig CA, Johnston M, McMurdo MET, et al. A systematic review of perceived barriers and motivators to physical activity after stroke. International Journal of Stroke 2013;8:357-64.

\section{Nocon 2008}

Nocon M, Hiemann T, Muller-Riemenschneider F, Thalau F, Roll S, Willich SN. Association of physical activity with all-cause and cardiovascular mortality: a systematic review and meta- analysis. European Journal of Cardiovascular Prevention and Rehabilitation 2008;15:239-46.

\section{O'Donnell 2016}

O'Donnell MJ, Chin SL, Rangarajan S, Xavier D, Liu L, Zhang H, INTERSTROKE investigators. Global and regional effects of potentially modifiable risk factors associated with acute stroke in 32 countries (INTERSTROKE): a case-control study. Lancet 2016;388:761-75.

\section{Owen 2010}

Owen N, Healy GN, Matthews CE, Dunstan DW. Too much sitting: the population-health science of sedentary behavior. Exercise and Sport Science Reviews 2010;38:105-13.

\section{Pollock 2014}

Pollock A, Baer G, Campbell P, Choo PL, Forster A, Morris J, et al. Physical rehabilitation approaches for the recovery of function and mobility following stroke. Cochrane Database of Systematic Reviews 2014, Issue 4. [DOI: 10.1002/14651858.CD001920.pub3]

\section{RevMan 2014 [Computer program]}

Nordic Cochrane Centre, The Cochrane Collaboration. Review Manager 5 (RevMan 5). Version 5.3. Copenhagen: Nordic Cochrane Centre, The Cochrane Collaboration, 2014.

\section{Samitz 2011}

Samitz G, Egger M, Zwahlen M. Domains of physical activity and all-cause mortality: systematic review and dose-response metaanalysis of cohort studies. International Journal of Epidemiology 2011;40:1382-400.

\section{SUTC 2013}

Stroke Unit Trialists' Collaboration. Organised inpatient (stroke unit) care for stroke. Cochrane Database of Systematic Reviews 2013, Issue 9. [DOI: 10.1002/14651858.CD000197.pub3]

\section{Tremblay 2010}

Tremblay MS, Colley RC, Saunders TJ, Healy GN, Owen N. Physiological and health implications of a sedentary lifestyle. Applied Physiology, Nutrition, and Metabolism 2010;35:725-40.

\section{Veerbeek 2014}

Veerbeek JM, van Wegen E, van Peppen R, van der Wees PJ, Hendriks E, Rietberg M, et al. What is the evidence for physical therapy poststroke? A systematic review and meta-analysis. PLoS One 2014;9(2):e87987.

\section{Walker 2017}

Walker MF, Hoffman TC, Brady MC, Dean CM, Eng JJ, Farrin AJ, et al. Improving the development, monitoring and reporting of stroke rehabilitation research: consensus-based core recommendations from the Stroke Recovery and Rehabilitation Roundtable. International Journal of Stroke 2017;12(5):472-9.

\section{West 2012}

West T, Bernhardt J. Physical activity in hospitalised stroke patients. Stroke Research and Treatment 2012;2012:813765. 


\section{Woodcock 2011}

Woodcock J, Franco OH, Orsini N, Roberts I. Non-vigorous physical activity and all-cause mortality: systematic review and meta-analysis of cohort studies. International Journal of Epidemiology 2011;40:121-38.

* Indicates the major publication for the study

\section{CHARACTERISTICS OF STUDIES}

Characteristics of included studies [ordered by study ID]

\section{Danks 2016}

Methods

Study design: randomised controlled trial

Study grouping: parallel group

Aim of study: to determine preliminary efficacy and to identify baseline characteristics predicting who would benefit most from fast-walking training plus a step activity monitoring program (FAST + activity monitoring) compared with fast-walking training alone (FAST) in people with chronic stroke

Unit of allocation: randomised at the individual participant level

Duration of participation: 30 minutes, 3 times per week for 12 weeks (36 sessions)

Ethical approval obtained for study: approved by the Human Subjects Review Board at the University of Delaware

Blinding: all outcome measurements were performed by a blinded assessor

Physical activity monitor/s used: StepWatch activity monitor

Participants

Baseline characteristics

Other intervention alone (FAST-only)

- Age, years: $58.2 \pm 12.4$

- Sex: 6 women, 8 men

- Side of stroke: 9 left, 5 right

- Time since stroke: $50.8 \pm 44.1$ months

- Lower Extremity Fugl-Meyer Score (out of 34): $18.6 \pm 4.6$

Activity monitor plus other intervention (FAST + activity monitoring)

- Age, years: $59.1 \pm 8.7$

- Sex: 6 women, 7 men

- Side of stroke: 7 left, 6 right

- Time since stroke: $29.4 \pm 21.4$ months

- Lower Extremity Fugl-Meyer Score (out of 34): $16.8 \pm 7.1$

Overall

- Age, years: not reported

- Sex: 12 women, 15 men

- Side of stroke: 16 left, 11 right

- Time since stroke: not reported

- Lower Extremity Fugl-Meyer Score (out of 34): not reported

Inclusion criteria: individuals aged 21 to 85 years were included in the study if they (1) had sustained a stroke > 6 months prior; (2) were able to walk without assistance (the use of orthotics or assistive devices was allowed); (3) were able to walk 5 minutes at a self-selected pace on the treadmill; (4) were able to walk outside the home before stroke; (5) walked less than 10,000 steps per day; and (6) were able to communicate with the investigators 
Exclusion criteria: (1) had experienced > 1 stroke; (2) had evidence of a cerebellar stroke; (3) had additional neurologic diseases; (4) had a cardiac event within last 3 months; (5) had received botulinum toxin type A in the lower extremities within past 4 months; (6) had pain that limited walking; (7) had unexplained dizziness in the past 6 months; or (8) were participating in skilled physical therapy services

Pretreatment: at baseline, there were no statistically significant differences in age or time since stroke between groups

Setting: university-based laboratory

Method of recruitment of participants: recruited from local physical therapy clinics, stroke support groups and newspaper advertisements

Informed consent obtained: unclear

Total number randomised: 37 (19 to FAST + activity monitoring; 18 to FAST-only)

Withdrawals and exclusions: 70 assessed for eligibility, 33 excluded ( 7 did not meet inclusion criteria, 25 declined to participate, 1 other reason)

FAST + activity monitoring: 6 withdrawals: 2 did not receive intervention because did not pass cardiac stress test, 4 discontinued intervention (poor attendance $n=1$, exacerbation of pain from previous injury $n=2$, seizure requiring hospitalisation $n=1$ )

FAST-only: 4 withdrawals: 1 did not receive intervention due to fall with fracture prior to starting, 3 discontinued intervention (poor attendance $n=2$, car accident resulting in fracture $n=1$ )

Subgroups measured and/or reported: nil

Interventions

\section{Intervention characteristics}

Other intervention alone (FAST-only)

- Wearing of activity monitor: Stepwatch Activity Monitor worn during all training sessions for 12 weeks

- Walking training: 30 minute sessions: fast-walking treadmill training programme (wearing overhead chest harness system, no body weight support provided) followed directly by 10 minutes of overground walking activities. Participants walked for 30 minutes with the goal of walking at the fast training speed within a target heart rate $(\mathrm{THR})$, calculated as THR $=([220-$ age $]-$ resting heart rate $) \times 80 \%$ resting heart rate

Activity monitor plus other intervention (FAST + activity monitoring)

- Wearing of activity monitor: Stepwatch Activity Monitor worn throughout the 12-week training programme

- Walking training: 30-minute sessions: fast-walking treadmill training programme (wearing overhead chest harness system, no body weight support provided) followed directly by 10 minutes of overground walking activities. Participants walked for 30 minutes with the goal of walking at the fast training speed within a target heart rate (THR), calculated as THR $=([220-$ age $]-$ resting heart rate $) \times 80 \%$ resting heart rate

- Activity monitoring program: baseline step activity data were used to categorise and assign individual participants' step activity goals. Participants were asked to increase walking activity by $8 \%$ if completing an average of up to 5000 steps/day, increase walking activity by $5 \%$ if averaging between 5000 and 7499 steps/day and increase walking activity by $3 \%$ if averaging between 7500 and 9999 steps/day

- Participants were expected to achieve their daily step goal on the days that they did not attend treadmill training sessions. For those who were able to attain six days of goal achievement over a 2-week period, a new activity goal was calculated based on the average steps/day completed in the second week of the 2-week monitoring period

- Feedback to participants: step activity data (numbers of steps/day on non-treadmill training days) were reviewed at each treadmill training session and used to determine and promote goal achievement. An individualised discussion of barriers to increased activity and how to overcome those barriers occurred at each session 
Danks 2016 (Continued)

- Additional intervention components: physical therapists discussed specific topics (e.g. education on the benefits of activity and risks of inactivity, monitoring a sedentary lifestyle and substituting activity for inactivity) during the 2-week goal advancement session

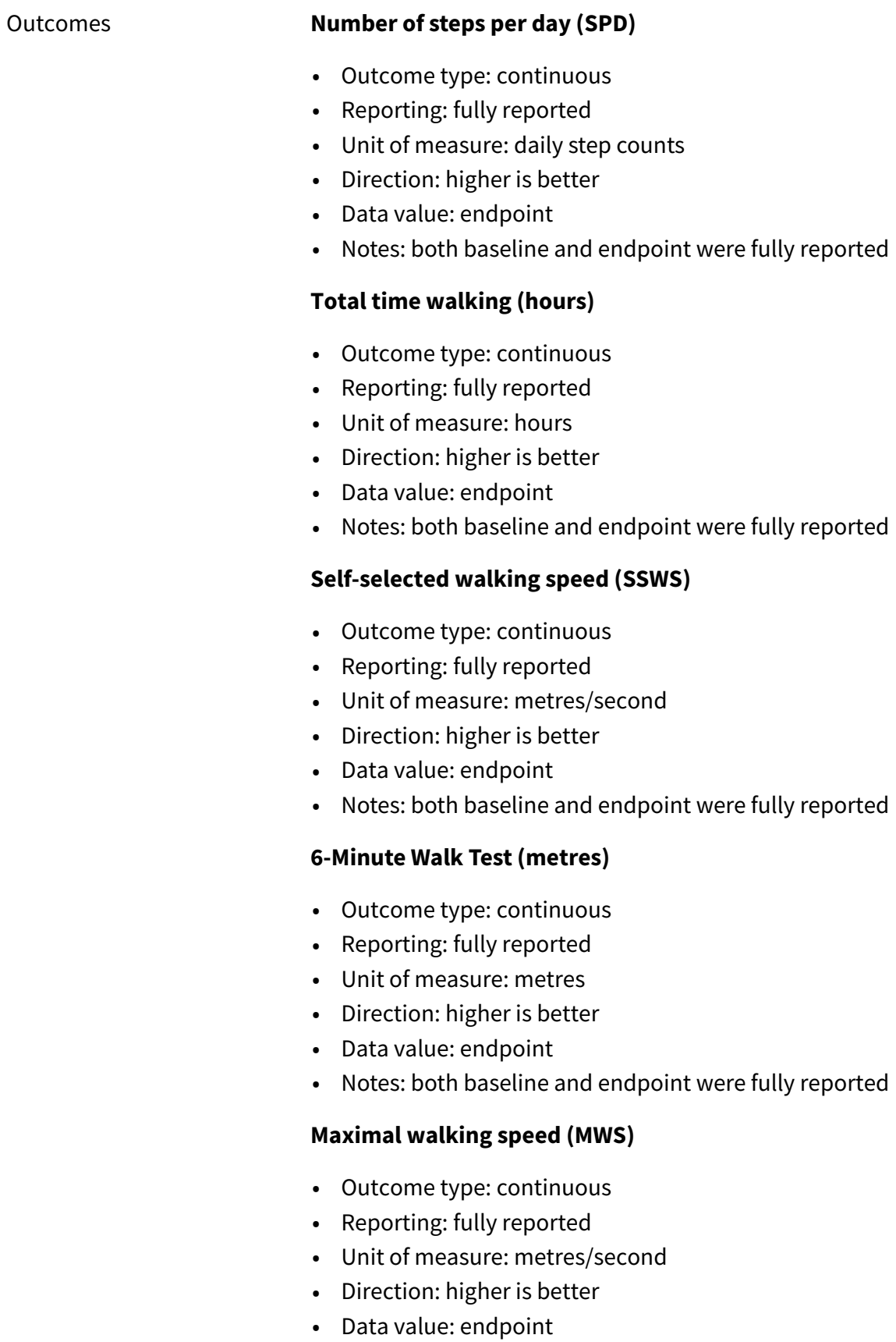

Outcomes

Number of steps per day (SPD)

- Outcome type: continuous

- Reporting: fully reported

- Unit of measure: daily step counts

- Direction: higher is better

- Data value: endpoint

- Notes: both baseline and endpoint were fully reported

Total time walking (hours)

- Outcome type: continuous

- Reporting: fully reported

- Unit of measure: hours

- Direction: higher is better

- Data value: endpoint

- Notes: both baseline and endpoint were fully reported

\section{Self-selected walking speed (SSWS)}

- Outcome type: continuous

- Reporting: fully reported

- Unit of measure: metres/second

- Direction: higher is better

- Data value: endpoint

- Notes: both baseline and endpoint were fully reported

6-Minute Walk Test (metres)

- Outcome type: continuous

- Reporting: fully reported

- Unit of measure: metres

- Direction: higher is better

- Data value: endpoint

- Notes: both baseline and endpoint were fully reported

\section{Maximal walking speed (MWS)}

- Outcome type: continuous

- Reporting: fully reported

- Unit of measure: metres/second

- Direction: higher is better

- Data value: endpoint

Sponsorship source: supported by the National Institutes of Health (grant no. R21HD07142). Publication of article was supported by the American Congress of Rehabilitation Medicine

Country: USA

Setting: outpatient clinical research laboratory

Comments: participants were recruited from local physical therapy clinics, stroke support groups, and newspaper advertisements. Participants completed outcome assessment in a university-based laboratory 
Danks 2016 (Continued)

Authors name: Darcy S Reisman

Institution: University of Delaware

Email: dreisman@udel.edu

Address: 540 S, College Ave, Newark, DE 19713, USA

\section{Notes}

\section{Risk of bias}

\begin{tabular}{|c|c|c|}
\hline Bias & Authors' judgement & Support for judgement \\
\hline $\begin{array}{l}\text { Random sequence genera- } \\
\text { tion (selection bias) }\end{array}$ & Unclear risk & Generation technique of random sequence was not discussed \\
\hline $\begin{array}{l}\text { Allocation concealment } \\
\text { (selection bias) }\end{array}$ & Unclear risk & There was no specific discussion regarding allocation concealment \\
\hline $\begin{array}{l}\text { Blinding of participants } \\
\text { and personnel (perfor- } \\
\text { mance bias) } \\
\text { All outcomes }\end{array}$ & High risk & $\begin{array}{l}\text { Blinding of personnel not possible and blinding of participants to true nature } \\
\text { of study was unclear }\end{array}$ \\
\hline $\begin{array}{l}\text { Blinding of outcome as- } \\
\text { sessment (detection bias) } \\
\text { All outcomes }\end{array}$ & Low risk & $\begin{array}{l}\text { All outcome measurement testing was done by an investigator blinded to } \\
\text { group assignment }\end{array}$ \\
\hline $\begin{array}{l}\text { Incomplete outcome data } \\
\text { (attrition bias) } \\
\text { All outcomes }\end{array}$ & Low risk & $\begin{array}{l}\text { All participants were accounted for, with none lost to follow-up, reasons were } \\
\text { clearly given as to withdrawal and exclusion from study }\end{array}$ \\
\hline $\begin{array}{l}\text { Selective reporting (re- } \\
\text { porting bias) }\end{array}$ & Low risk & Table 2 presented all data in full \\
\hline Other bias & Low risk & - \\
\hline
\end{tabular}

\section{Dorsch 2015}

\section{Methods}

Study design: randomised controlled trial

Study grouping: parallel group

Aim of study: to test the feasibility of providing quantitative feedback about daily walking performance and motivating greater skills practice via remote sensing in inpatient stroke rehabilitation

Unit of allocation: randomised at the individual participant level, block randomisation design was used

Duration of participation: commenced participation when met eligibility criteria (within 10 days of admission) and continued until discharge from inpatient rehabilitation. Median trial participation time 20 days in speed-only feedback group and 22.5 days in activity monitor plus speed feedback group

Ethical approval obtained for study: ethical approval was granted by each site's local institutional review board. The study was registered at ClinicalTrials.gov (NCT01246882)

Blinding: all outcome measurements were performed by a blinded assessor 
Physical activity monitor used: triaxial accelerometers (Gulf Coast Data Concepts, Waveland, MS) worn with 1 sensor on each ankle

\section{Participants}

\section{Baseline Characteristics}

Other intervention alone (speed-only feedback)

- Age, years: $65.0 \pm 13.2$

- Sex: 59 women, 92 men

- Stroke type, $\mathrm{n}(\%)$ : large vessel ischaemic 41 (56.2); lacunar 11 (15.0); haemorrhagic 14 (19.2); unknown 7 (9.6)

- Hemiparetic side, n (\%): R 42 (59.2), L 29 (40.8)

- Second stroke, $\mathrm{n}(\%): 4$ (5.5)

- Time from stroke to rehabilitation, days, median (Interquartile range, IQR): 8.5 (4.2 to 14.8)

- National Institutes of Health Stroke Scale (NIHSS), median (IQR): 6 (4 to 9)

- Functional Ambulation Classification (FAC) score, $\mathrm{n}(\%): 0: 6$ (9.0); 1: 21 (31.2); 2: 20 (30.0); 3: 9 (13.4); 4: 9 (13.4); 5: 2 (3.0)

- 15-metre walk speed, $\mathrm{m} / \mathrm{s}: 0.52 \pm 0.47$

- 3-minute walk distance, m: $79.7 \pm 68.5$

- Rehabilitation length of stay, days, median (IQR): 25 (18 to 36.5)

Activity monitor plus other intervention (activity monitoring + speed feedback)

- Age, years: $61.8 \pm 15.7$

- Women, $\mathrm{n}(\%): 31(40.3)$

- Stroke type, $\mathrm{n}(\%)$ : large vessel ischaemic 45 (57.7); lacunar 18 (23.0); haemorrhagic 13 (16.7); unknown 2 (2.6)

- Hemiparetic side, $\mathrm{n}(\%)$ : right 44 (56.4), left 34 (43.6)

- Second stroke, $\mathrm{n}(\%): 3$ (3.9)

- Time from stroke to rehabilitation, days, median (IQR): 8 (5 to 16)

- NIHSS, median (IQR): 6 (4 to 7 )

- FAC score, n (\%): 0: 6 (8.2); 1: 28 (38.4); 2: 19 (26.0); 3: 8 (11.0); 4: 7 (9.6); $5: 5$ (6.8)

- 15-metre walk speed, $\mathrm{m} / \mathrm{s}: 0.52 \pm 0.45$

- 3-minute walk distance, m: $80.9 \pm 67.5$

- Rehabilitation length of stay, days, median (IQR): 25 (17 to 36)

Overall

- Age, years: not reported

- Women, n (\%): 59 (39.1)

- Stroke type, n (\%): large vessel ischaemic 86 (57.0); lacunar 29 (19.2); haemorrhagic 27 (17.9); unknown 9 (6.0)

- Hemiparetic side, $\mathrm{n}(\%)$ : right 86 (57.0); left 63 (41.7)

- Second stroke, $\mathrm{n}(\%): 7$ (5.0)

- Time from stroke to rehabilitation, days, median: 9

- NIHSS, median (IQR): 6 (4 to 8)

- FAC score, n (\%): 0:12 (8.6); 1:49 (35); 2:39 (27.9); 3:17 (12.1); 4:16 (11.4); 5:7 (5.0)

- 15-metre walk speed, m/s: 0.46

- 3-minute walk distance, $\mathrm{m}: 85.8$

- Rehabilitation length of stay, days, median: 25

Inclusion criteria: people with stroke with residual hemiparesis were eligible if they could walk 5 steps within 10 days of admission to inpatient rehabilitation, and were admitted to the inpatient rehabilitation facility within 35 days of stroke. Patients with previous stroke were eligible to participate if they had experienced full motor recovery 
Exclusion criteria: aphasia limiting the ability to follow 2-step commands and ongoing medical disease limiting participation in physical therapy

Pretreatment: at baseline, there were no statistically significant differences in age, sex, stroke location, or disability between groups

Setting: inpatient rehabilitation centres: 4 within USA, 12 international

Method of recruitment of participants: recruited from inpatient rehabilitation units - specific process of recruitment not described

Informed consent obtained: all participants provided written informed consent prior to participation

Total number randomised: 151 (73 to speed-only feedback, 78 to activity monitoring + speed feedback), 125 completed study (58 speed-only feedback, 67 activity monitoring + speed feedback)

Withdrawals and exclusions: 156 screened for eligibility, 5 excluded ( 2 with minimal paresis; 1 with aphasia; 1 with residual deficits from prior stroke; 1 unknown)

Speed-only feedback: 10 received no intervention ( $n=10$ from SF group; 6 withdrawn by day 3 admission, 4 admitted $>35$ days poststroke), 5 did not complete study ( 2 cardiac adverse events, 1 neurologic adverse events, 1 sensor failure, 1 refusal to continue)

Activity monitoring + feedback: 6 received no intervention ( 5 withdrawn by day 3 admission, 1 admitted $>35$ days poststroke), 5 did not complete study ( 1 unspecified adverse event, 1 refusal to continue, 1 left hospital against medical advice, 2 unknown)

Subgroups measured, reported, or both: functional impairment groups - based on mean baseline 15 $\mathrm{m}$ walking speed: $0.13 \mathrm{~m} / \mathrm{s}=$ severely affected, $0.38 \mathrm{~m} / \mathrm{s}=$ moderately affected, and $1.12 \mathrm{~m} / \mathrm{s}=$ mildly affected

Method of randomisation: randomly assigned to a speed-only feedback or speed feedback plus activity monitor feedback trial arm by a computer using a concealed allocation sequence. A block randomisation design was employed to achieve equal group numbers at each study site

\section{Intervention characteristics}

Other intervention alone

- Speed feedback: accelerometer worn each day from before getting out of bed until back in bed at end of the day (weekend use was optional). Activity classified and recorded by gait system. Three times a week after performing a fast 10-metre walk test, all participants received standardised verbal feedback, for example, "Very good! You walked that in (number of) seconds"

- Participation in trial, days, median (IQR): 20 (14 to 33)

- Days with processed sensor data, days, median (IQR): 10 (7 to 18.5)

- Daily activity monitoring, hours, median (IQR): 8.7 (7.8 to 10.8$)$

Activity monitor plus other intervention

- Speed feedback: accelerometer worn each day from before getting out of bed until back in bed at end of the day (weekend use was optional). Activity classified and recorded by gait system. Three times a week after performing a fast 10-metre walk test, all participants received standardised verbal feedback, for example, "Very good! You walked that in (number of) seconds"

- Intervention programme: personalised bar graphs summarising daily step count, average and maximum walking speed, and distance walked were reviewed by participants with the therapists. Using a scripted statement, therapists encouraged these patients to meet or exceed their prior activity levels. For example "You are showing some improvement" or "You have not yet increased your (walking speed, distance, steps), let's see if you can make further improvements today"

- Participation in trial, days, median (IQR): 22.5 (13.8 to 31)

- Days with processed sensor data, days, median (IQR): 13 (9 to 18.8)

- Daily activity monitoring, hours, median (IQR): 8.7 (7.9 to 9.9) 
Dorsch 2015 (Continued)

Outcomes

\section{3-MWT (metres)}

- Outcome type: continuous outcome

- Reporting: fully reported

- Scale: distance

- Unit of measure: metres

- Direction: higher is better

- Data value: endpoint

\section{Functional Ambulation Category (FAC)}

- Outcome type: dichotomous outcome

- Reporting: fully reported

- Range: 0 to 5

- Unit of measure: $\geq 4$

- Direction: higher is better

- Data value: endpoint

- Notes: 0 = nonfunctional ambulation; 1 = manual assistance, heavy; 2 = manual assistance, light; $3=$ stand-by assistance; 4 = assistance for stairs; 5 = independent

\section{Stroke Impact Scale (SIS-16)}

- Outcome type: continuous outcome

- Reporting: partially reported

- Range: 16 to 80

- Direction: higher is better

- Data value: endpoint

- Notes: participant perception of function; 16 questions scored from 1 to 5

Total daily walking time (minutes)

- Outcome type: continuous outcome

- Reporting: partially reported

- Unit of measure: minutes

- Direction: higher is better

- Data value: endpoint

\section{5-metre walking speed}

- Outcome type: continuous outcome

- Reporting: fully reported

- Unit of measure: metres

- Direction: higher is better

- Data value: endpoint

Time in longer walking bouts ( $\geq 2$ minutes)

- Outcome type: continuous outcome

- Reporting: partially reported

- Scale: time spent in walking in longer bouts ( $\geq 2$ minutes)

- Unit of measure: minutes

- Direction: higher is better

- Data value: endpoint 
Setting: inpatient rehabilitation setting

Comments: $\mathrm{n} / \mathrm{a}$

Authors name: Bruce H Dobkin

Institution: Department of Neurology, Geffen School of Medicine, University of California Los Angeles

Email: bdobkin@mednet.ucla.edu

Address: Department of Neurology, Geffen School of Medicine, University of California Los Angeles, RNRC, Room 1-129, 710 Westwood Plaza, Los Angeles, CA 90095, USA

\section{Notes}

\section{Risk of bias}

\begin{tabular}{lll}
\hline Bias & Authors' judgement & Support for judgement \\
\hline $\begin{array}{l}\text { Random sequence genera- } \\
\text { tion (selection bias) }\end{array}$ & Low risk & $\begin{array}{l}\text { Quote: "After eligibility criteria were entered into the central database, partic- } \\
\text { ipants were assigned to a speed-only feedback or augmented feedback trial } \\
\text { arm by a computer using a concealed allocation sequence. A block randomiza- } \\
\text { tion design was employed to achieve equal group numbers at each study site." }\end{array}$ \\
\hline $\begin{array}{l}\text { Allocation concealment } \\
\text { (selection bias) }\end{array}$ & Low risk & Concealed allocation sequence \\
\hline
\end{tabular}

Blinding of participants $\quad$ High risk $\quad$ Blinding of personnel not possible. Participants were fully informed
and personnel (perfor-
mance bias)

\begin{tabular}{lll}
\hline $\begin{array}{l}\text { Blinding of outcome as- } \\
\text { sessment (detection bias) } \\
\text { All outcomes }\end{array}$ & Low risk & $\begin{array}{l}\text { Blinded observers collected a stopwatch-timed 15-metre walk, the distance } \\
\text { walked in 3 minutes, and Functional Ambulation Category (FAC) score. }\end{array}$ \\
\hline $\begin{array}{l}\text { Incomplete outcome data } \\
\begin{array}{l}\text { (attrition bias) } \\
\text { All outcomes }\end{array}\end{array}$ & Low risk & $\begin{array}{l}\text { All participants were accounted for, with none lost to follow-up, reasons were } \\
\text { clearly given as to withdrawal or exclusion from study }\end{array}$ \\
\hline $\begin{array}{l}\text { Selective reporting (re- } \\
\text { porting bias) }\end{array}$ & Low risk & All final data reported \\
\hline Other bias & Low risk & - \\
\hline
\end{tabular}

Kanai 2018

Study design: randomised controlled trial
Study grouping: parallel group
Aim of study: to evaluate the effect of accelerometer-based feedback on physical activity in hospi-
talised patients with ischaemic stroke.

Unit of allocation: randomised at individual participant level 
Duration of participation: from enrolment (mean 4 days after admission) until discharge from inpatient rehabilitation. During inpatient stay, received 40 to 120 minutes of supervised rehabilitation 5 to 6 times/week. Mean length of hospital stay 11 to 12 days

Ethical approval obtained for study: the study was approved by the Itami Kousei Neurosurgical Hospital Research Ethics Committee (approval no. 20140002)

Blinding: treating therapists were not blinded to patient allocation. Data for 3 of 4 outcomes were collected using objective accelerometer based measure. Fourth outcome measure collected by physical therapists who were aware of which patients were in the intervention group and the control group

Physical activity monitor used: Fitbit One

Participants

\section{Baseline Characteristics}

Other intervention alone (usual inpatient rehabilitation)

- Age, years: $62.9 \pm 9.1$

- Sex: 12 women, 13 men

- Stroke type, n: large artery atherosclerosis 4; cardioembolic 2; small vessel occlusion 18; undetermined 1

- Hemiparetic side, $\mathrm{n}(\%)$ : right 11 (44), left 14 (56)

- Time from admission to study enrolment, days: $3.8 \pm 1.5$

- National institutes of Health Stroke Scale (NIHSS): $1.0 \pm 1.0$

- Walking speed m/s: $1.1 \pm 0.3$

- Berg Balance Scale, score: $54.7 \pm 1.7$

- Length of hospital stay, days: $11.4 \pm 3.9$

Activity monitor plus other intervention (rehabilitation with accelerometer-based feedback)

- Age, years: $66.8 \pm 10.0$

- Sex: 8 women, 15 men

- Stroke type, n: large artery atherosclerosis 6; cardioembolic 1 ; small vessel occlusion 16

- Hemiparetic side, $\mathrm{n}(\%)$ : right 9 (39.1), left 13 (56.5), bilateral 1 (4.3)

- Time from admission to study enrolment, days: $3.6 \pm 1.4$

- NIHSS: $0.9 \pm 0.8$

- Walking speed $\mathrm{m} / \mathrm{s}: 1.1 \pm 0.2$

- Berg Balance Scale, score: $54.1 \pm 2.1$

- Length of hospital stay, days: $12.2 \pm 2.8$

Overall

- Age, years: not reported

- Sex: 20 women, 28 men

- Stroke type, n: large artery atherosclerosis 10; cardioembolic 3; small vessel occlusion 34, undetermined 1

- Hemiparetic side: right 22, left 25, bilateral 1

- Time from admission to study enrolment, days: not reported

- NIHSS: not reported

- Walking speed: not reported

- Berg balance scale: not reported

- Length of hospital stay: not reported

Inclusion criteria: acute ischaemic stroke on MRI or CT imaging, able to walk without assistance or gait aid within 1 week of admission

Exclusion criteria: aphasia, visual field defect, dementia (Mini-Mental State Examination score $<23$ ), age $>80$ years old, premorbid modified Rankin Scale $(\mathrm{mRS})$ score $>2$ due to a history of musculoskele- 

study

Pretreatment: no significant differences between groups at baseline in terms of any of the collected outcome measures

Setting: inpatient hospital

Method of recruitment of participants: consecutive patients in acute phase of ischaemic stroke admitted to Itami Kousei Neurosurgica Hospital within 48 hours from stroke onset who underwent rehabilitation from April 2016 to March 2017 were enrolled - specific process of recruitment not described

Informed consent obtained: not specified

Total number randomised: 55 ( 27 to rehabilitation with accelerometer-based feedback, 28 to usual rehabilitation), 48 completed the study ( 23 in rehabilitation with accelerometer-based feedback, 25 in usual rehabilitation)

Withdrawals and exclusions: 133 screened for eligibility, 78 excluded (34 older than 80 years old, 19 with premorbid $\mathrm{mRS}>2,11$ declined to participate, 8 aphasia or cognitive impairment, and 6 for other reasons). 7 dropped out; 4 from rehabilitation with accelerometer-based feedback group (1 did not wear accelerometer, 1 declined to participate, 2 for other reasons) and 3 from usual rehabilitation group ( 2 withdrew with less than 3 days of monitoring, 1 declined to participate)

Subgroups measured and/or reported: not specified

Other intervention alone (inpatient rehabilitation)

- All participants wore accelerometer (Fitbit One) on waist belt 24 hours/day until discharge, unless bathing

- All participants underwent 40 to 120 minutes of supervised rehabilitation 5 to 6 times/week. This consisted of physical therapy and occupational therapy: body stretches, body weight resistance exercise (shoulder flexion and abduction from anatomic position, squats and calf raises), aerobic exercise (40\% to $60 \%$ of maximum predicted heart rate or at intensity of 11 to 13 on Borg scale on cycle ergometer) and a cool-down period

- Participants who needed to improve balance, walking, or activities of daily living received specific exercise instruction.

Activity monitor plus other intervention (rehabilitation with accelerometer-based feedback)

- Usual inpatient rehabilitation as described above

- After baseline measurement, participants instructed in use of accelerometer-based feedback to promote hospitalised physical activity: asked by physical therapist to record measured activity on calendar

- Participant and therapist set activity targets including steps/day (typically 100 to 500 steps more than previous day) or objective activity

- Participant had access to real time feedback on steps, to help achieve daily targets

- Physical therapist and patient reviewed daily activity - participant praised if target achieved, if target not achieved the physical therapist discussed a modified activity target with participant by viewing the feedback log

- Outcome type: continuous

- Reporting: fully reported

- Unit of measure: number of steps

- Direction: higher is better

- Data value: endpoint

- Notes: data collected via downloading data files to Fitbit online dashboard software 
Kanai 2018 (Continued)

\section{Exercise energy expenditure}

- Outcome type: continuous

- Reporting: fully reported

- Unit of measure: kcal

- Direction: higher is better

- Data value: endpoint

- Notes: data collected via downloading data files to Fitbit online dashboard software

Duration of activity time

- Outcome type: continuous

- Reporting: fully reported

- Unit of measure: minutes/day in light, moderate, and vigorous activity

- Direction: higher is better

- Data value: endpoint

- Notes: data collected via downloading data files to Fitbit online dashboard software. Duration of activity time calculated for each intensity (light, moderate and vigorous)

\section{Self-efficacy for physical activity}

- Outcome type: 4 subscales with subscale scores ranging from 0 to 100

- Reporting: fully reported

- Unit of measure: score out of 400

- Direction: higher is better

- Data value: endpoint

- Notes: data collected using Japanese version of self-efficacy for physical activity score

Identification

Sponsorship source: author(s) disclosed receipt of the following financial support for the research, authorship and/or publication of the article: Sasakawa Scientific Research Grant (grant no, 28-622) from the Japan Science Society

Country: Japan

Setting: inpatient hospital

Comments: $\mathrm{n} / \mathrm{a}$

Authors name: Kazuhiro P Izawa

Institution: Department of International Health Sciences, Graduate School of Health Sciences, Kobe University, Kobe, Japan

Email: izawapk@harbor.kobe-u.ac.jp

Address: Department of International Health Sciences, Graduate School of Health Sciences, Kobe University, 7-10-2 Tomogaoka, Suma-ku, Kobe 654-0142, Japan

Notes

\section{Risk of bias}

Bias Authors' judgement Support for judgement

Random sequence genera- Low risk tion (selection bias)
An independent person who was not involved in enrolment or outcome assessment performed the randomisation using a computer-generated 1:1 allocation sequence and permuted block size of 2 . Participants were randomly assigned to the intervention group or control group by this independent person. The sequence was concealed until intervention 
Kanai 2018 (Continued)

\begin{tabular}{lll}
$\begin{array}{l}\text { Allocation concealment } \\
\text { (selection bias) }\end{array}$ & Low risk & As above \\
\hline $\begin{array}{l}\text { Blinding of participants } \\
\begin{array}{l}\text { and personnel (perfor- } \\
\text { mance bias) }\end{array}\end{array}$ & High risk & Unable to blind participants, therapists were not blinded \\
All outcomes &
\end{tabular}

\begin{tabular}{lll}
\hline $\begin{array}{l}\text { Blinding of outcome as- } \\
\text { sessment (detection bias) } \\
\text { All outcomes }\end{array}$ & Low risk & $\begin{array}{l}\text { 3 of } 4 \text { outcomes collected via objective accelerometer. Physical therapists who } \\
\text { were aware of participants' group allocations collected outcomes on self-effi- } \\
\text { cacy for physical activity }\end{array}$ \\
\hline $\begin{array}{l}\text { Incomplete outcome data } \\
\text { (attrition bias) } \\
\text { All outcomes }\end{array}$ & Low risk & Small study, patient withdrawals balanced between groups \\
\hline $\begin{array}{l}\text { Selective reporting (re- } \\
\text { porting bias) }\end{array}$ & Low risk & $\begin{array}{l}\text { All activity outcomes that would be collected during hospital stay from trial } \\
\text { protocol reported. Planned outcomes that were not recorded: stroke recur- } \\
\text { rence, other cardiovascular event, post-discharge physical activity }\end{array}$ \\
\hline Other bias & Low risk & \\
\hline
\end{tabular}

Study design: randomised controlled trial

Study grouping: parallel group

Aim of study: to determine the benefit of providing feedback regarding characteristics of patients' daily walking activity to their physiotherapists as part of a goal-setting process

Unit of allocation: assigned by participants in blocks of 4 to feedback or no feedback

Duration of participation: time of enrolment to inpatient discharge (3 to 26 days of monitoring; mode $=11$ days)

\section{Ethical approval obtained for study: yes}

Dates of study: October 2012 to January 2014

Blinding: a blinded research assistant screened and enrolled participants, conducted the assessments, processed data, and generated reports. Reports for feedback participants were delivered to the physiotherapist by an investigator who was not involved in data collection

Physical activity monitor used: lightweight commercially available triaxial accelerometers (Model X6-2mini, Gulf Data Concepts, LLC, Waveland, MS)

\section{Participants}

\section{Baseline characteristics}

Other intervention alone (usual inpatient stroke rehabilitation)min to max

- Age, years, median (interquartile range, IQR; min to max): 61.5 (13; 24 to 81 )

- Sex: 12 women, 16 men

- Time since stroke, days, median (IQR; min to max): 23 (20; 12 to 72 )

- Stroke type: 22 ischaemic, 6 haemorrhagic

- Side of stroke: 13 left, 13 right, 2 bilateral

- National Institutes of Health Stroke Scale, median (IQR; min to max): 1 (3; 0 to 6)

- Berg Balance Scale, median (IQR; min to max): 39.5 (15; 4-56) 
- Chedoke-McMaster Stroke Assessment leg score, median (IQR; min to max): 4 (2; 3 to 7)

- Walking speed, $\mathrm{m} / \mathrm{s}$, median (IQR; $\min$ to max): 0.52 (0.41; 0.28 to 1.45 )

- Usual gait aid: 5 none, 5 cane, 15 wheeled walker-rollator, 3 multiple

- Time from admission to study enrolment, days, median (IQR; $\min$ to max): 12 (10; 3 to 42)

- Time from enrolment to discharge, days, median (IQR; min to max): 14 (9; 3 to 36)

- Number days monitored, median (IQR; $\min$ to $\max$ ): 8 ( $4 ; 3$ to 23 )

Activity monitor plus other intervention (usual inpatient rehabilitation + activity monitoring)

- Age, years, median (IQR; min to max): 64 (19; 22 to 92)

- Sex: 9 women, 20 men

- Time since stroke, days, median (IQR; min to max): 26 (22; 11 to 114$)$

- Stroke type: 24 ischaemic, 5 haemorrhagic

- Side of stroke: 16 left, 11 right, 2 bilateral

- National Institutes of Health Stroke Scale, median (IQR; min to max): 2 (2; 0 to 7)

- Berg Balance Scale, median (IQR; min to max): 38 (20; 4 to 56)

- Chedoke-McMaster Stroke Assessment leg score, median (IQR; min to max): 4 (2; 2 to 7)

- Walking speed, $\mathrm{m} / \mathrm{s}$, median (IQR; min to max): 0.75 (0.42; 0.15 to 1.27 )

- Usual gait aid: 8 none, 5 cane, 15 wheeled walker-rollator, 1 multiple

- Time from admission to study enrolment, days, median (IQR; min to max): 10 (15; 3 to 105 )

- Time from enrolment to discharge, days, median (IQR; min to max): 14 (13; 4 to 91)

- Number days monitored, median (IQR; min to max): 9 (6; 3 to 26 )

Overall

- Age, years, median (IQR; min to max): 63 (17; 22 to 92)

- Sex: 21 women, 36 men

- Time since stroke, days, median (IQR; $\min$ to max): 25 (20; 11 to 114 )

- Stroke type: 46 ischaemic, 11 haemorrhagic

- Side of stroke: 29 left, 24 right, 4 bilateral

- National Institutes of Health Stroke Scale, median (IQR; min to max): 2 (2; 0 to 7)

- Berg Balance Scale, median (IQR; min to max): 39 (20; 4 to 56)

- Chedoke-McMaster Stroke Assessment leg score, median (IQR; min to max): 4 (2; 2 to 7 )

- Walking speed, $\mathrm{m} / \mathrm{s}$, median (IQR; min to max): 0.69 (0.46; 0.15 to 1.45 )

- Usual gait aid: 13 none, 10 cane, 30 wheeled walker-rollator, 4 multiple

- Time from admission to study enrolment, days, median (IQR; min to max): 11 (13; 3 to 105)

- Time from enrolment to discharge, days, median (IQR; min to max): 14 (11; 3 to 91)

- Number days monitored, median (IQR; $\min$ to $\max$ ): 8 (5; 3 to 26 )

Inclusion criteria: individuals with subacute stroke attending inpatient rehabilitation at Toronto Rehab were recruited if they had a walking-related rehabilitation goal and were able to walk without supervision at the time of enrolment. People who were not ambulatory on admission were reassessed for eligibility 2 to 3 times per week until they either became eligible or were discharged

Exclusion criteria: individuals unable to provide consent were excluded

Pretreatment: at baseline, there were no statistically significant differences in age, sex, time since stroke or disability between groups

Method of recruitment: individuals with subacute stroke attending inpatient rehabilitation at Toronto Rehab were recruited

Total number randomised: 60 (29 to feedback + inpatient rehabilitation, 31 to inpatient rehabilitation only)

Withdrawals and exclusions: 238 screened for eligibility, 175 excluded after screening (138 did not meet inclusion criteria; 37 declined to participate) 3 were eligible but withdrew prior to randomisation. 
Inpatient rehabilitation only: 6 withdrawals: 2 due to early discharge, 1 due to a change in medical status, 2 declined further participation, and 1 repeatedly lost the accelerometers.

Feedback + inpatient rehabilitation: 3 withdrawals: 2 declined further participation, 1 due to a change in medical status.

Number for analysis of gait data at end of activity monitoring: $\mathrm{N}=35$

Dropouts: $\mathrm{n}=3$ (withdrew with less than 3 days of monitoring)

Informed consent obtained: provided written informed consent prior to participation

Setting: inpatient rehabilitation

Subgroups measured and/or reported: nil

\section{Intervention characteristics}

Other intervention alone

- Walking rehabilitation: physiotherapist assigned a walking programme of incrementally increasing difficulty based on rehabilitation goals. Participants received 1 hour of physiotherapy per day

- Goal-setting: physiotherapists had daily opportunities to discuss progress with physiotherapy-related rehabilitation goals (e.g. walking goals) with participants. In addition, participants met with their goal co-ordinators (assigned interprofessional team member) weekly to discuss progress with all rehabilitation goals. Daily individualised occupational therapy, speech and language pathology, group therapies, or a combination may have been prescribed to participants on an as-needed basis

- Feedback: physiotherapist relied on participant self-report for the appraisal portion of the goal-setting process

Activity monitor plus other intervention

- Walking rehabilitation: physiotherapist assigned a walking programme of incrementally increasing difficulty based on rehabilitation goals. Participants received 1 hour of physiotherapy per day

- Goal-setting: physiotherapists had daily opportunities to discuss progress with physiotherapy-related rehabilitation goals (e.g. walking goals) with participants. Additionally, participants met with their goal co-ordinators (assigned interprofessional team member) weekly to discuss progress with all rehabilitation goals. Daily individualised occupational therapy, speech and language pathology, and/or group therapies may have been prescribed to participants on an as-needed basis

- Feedback: a daily report was generated for each participant summarising the previous days' walking activity data. Reference values for target steps/day for various populations, and interpretation of cadence values were also provided. Physiotherapists of participants assigned to the activity monitor group received the walking activity report daily as means to appraise achievement of walking goals and subgoals.Walking reports were provided daily to physiotherapists from the second day of enrolment until the participant either withdrew or was discharged. Physiotherapists decided how best to use the information provided given participant-specific goals and language, communication, cognitive, and mobility impairments

Outcomes

Number of steps per day (SPD)

- Outcome type: continuous outcome

- Reporting: fully reported

- Unit of measure: number of steps

- Direction: higher is better

- Data value: endpoint

Total daily walking time (minutes)

- Outcome type: continuous outcome

- Reporting: fully reported

- Unit of measure: minutes 
- Direction: higher is better

- Data value: endpoint

\section{Average cadence (steps/min)}

- Outcome type: continuous outcome

- Reporting: fully reported

- Unit of measure: steps/minute

- Direction: higher is better

- Data value: endpoint

\section{Number of bouts $>5$ minutes long}

- Outcome type: continuous outcome

- Reporting: fully reported

- Unit of measure: number

- Direction: higher is better

- Data value: endpoint

\section{Longest bout duration (minutes)}

- Outcome type: continuous outcome

- Reporting: fully reported

- Unit of measure: minutes

- Direction: higher is better

- Data value: endpoint

Self-Selected Walking Speed (SSWS)

- Outcome type: continuous outcome

- Reporting: fully reported

- Unit of measure: metres/second

- Direction: higher is better

- Data value: endpoint

- Notes: taken on GAITRite over $4 \mathrm{~m}$

\section{Step length symmetry (ratio)}

- Outcome type: continuous outcome

- Reporting: fully reported

- Unit of measure: ratio of left and right

- Direction: lower is better

- Data value: endpoint

- Notes: larger number used as the numerator so all values were $>1$

\section{Swing time symmetry (ratio)}

- Outcome type: continuous outcome

- Reporting: fully reported

- Unit of measure: ratio of left and right

- Direction: lower is better

- Data value: endpoint

- Notes: larger number as numerator

Step length variability $(\mathrm{cm})$

- Outcome type: continuous outcome

- Reporting: fully reported 
- Unit of measure: centimetres

- Direction: lower is better

- Data value: endpoint

- Notes: variability was the average of the standard deviations for the left and right limbs

\section{Step time variability (ms)}

- Outcome type: continuous outcome

- Reporting: fully reported

- Unit of measure: milliseconds

- Direction: lower is better

- Data value: endpoint

- Notes: variability was the average of the standard deviations for the left and right limbs

\section{Step width variability $(\mathrm{cm})$}

- Outcome type: continuous outcome

- Reporting: fully reported

- Unit of measure: centimetres

- Direction: lower is better

- Data value: endpoint

- Notes: step width variability was the standard deviation of step width

\section{Stroke self-efficacy (score)}

- Outcome type: continuous outcome

- Reporting: fully reported

- Range: 0 to 10

- Unit of measure: score

- Direction: higher is better

- Data value: endpoint

- Notes: this 13-item questionnaire asks participants to rate confidence in completing various tasks, including walking indoors and outdoors, on a scale from 0 to 10

Identification

Sponsorship source: the Ontario Ministry of Health and Long-Term Care, the Ontario Stroke Network (OSN1101-000149), the Canada Foundation for Innovation, Ontario Innovation Trust, and the Ministry of Research and Innovation

Country: Canada

Setting: inpatient rehabilitation

Comments: the intervention was provided during inpatient rehabilitation

Authors name: Avril Mansfield

Institution: Toronto Rehabilitation Institute-University Health Network, Toronto, Ontario, Canada

Email: Avril.Mansfield@uhn.ca

Address: Toronto Rehabilitation Institute, Room 11-117, 550 University Ave, Toronto, Ontario, Canada M5G 2A2

Notes

\section{Risk of bias}


Mansfield 2015 (Continued)

Random sequence genera- Low risk Participants were randomly assigned using blocked stratified randomisation tion (selection bias)

(block size $=4$ ) to 1 of 2 groups.

Allocation concealment Low risk (selection bias)
Concealed group allocation was performed using a computer-generated random sequence by an investigator who was not involved in participant screening.

Blinding of participants High risk and personnel (perfor-

Reports for activity monitor participants were delivered to the physiotherapist by an investigator who was not involved in data collection. The physiotherapists administered goal-setting and planning, including incorporating the walking activity report for activity monitor feedback participants. Participants were not blinded.

All outcomes

A research assistant screened and enrolled participants, conducted the assess-

Blinding of outcome as- Low risk sessment (detection bias) ments, processed the data and generated reports.

All outcomes

Incomplete outcome data Low risk (attrition bias)

Number of participants were clearly indicated for all outcomes. Flow of partici-

All outcomes pants through the study was clearly outlined.

Selective reporting (re- Low risk
porting bias)

Tables 2 and 3 presented all outcome data as indicated.

Other bias Low risk Recruitment methods were sound and clear.

Characteristics of excluded studies [ordered by study ID]

\begin{tabular}{ll}
\hline Study & Reason for exclusion \\
\hline Bird 2016 & Wrong intervention \\
\hline Gandhi 2017 & Wrong study design \\
\hline Koh 2015 & Wrong comparator \\
\hline Martin 2015 & Wrong patient population \\
\hline Pandey 2013 & Wrong study design \\
\hline Paul 2016 & Wrong study design \\
\hline Sakakibara 2014 & Wrong comparator \\
\hline Seo 2015 & Wrong study design \\
\hline
\end{tabular}

Characteristics of ongoing studies [ordered by study ID]

\section{ACTRN12616001733460p}

Trial name or title
Feasibility study to evaluate a goal-directed physiotherapy-facilitated walking program for people after stroke to enhance health and well-being 
ACTRN12616001733460p (Continued)

Methods

Study design: randomised controlled trial

Study grouping: parallel

Aim: to investigate the feasibility of using a walking intervention to enhance health and well-being for people with stroke to inform a future RCT

Unit of allocation: not described

Duration of participation: 12 weeks

Ethical approval obtained for study: yes

Blinding: outcome assessors and data analysis

Physical activity monitor used: Fitbit one $\mathrm{T}^{\mathrm{TM}}$

Participants

Interventions

Inclusion: people with stroke living in the community (including rest homes) who are medically stable to embark on a walking programme and competent to provide written informed consent, as determined by their general practitioner (or medical professional). Participants must be independently ambulant (with or without mobility aids). Individuals under active treatment from a health professional will also be eligible as will those currently receiving no clinical intervention.

Exclusion: people with stroke requiring supervision or assistance to ambulate, those with cognitive impairment and unable to use a Fitbit on $\mathrm{e}^{\mathrm{TM}}$, inability to communicate in English

Method of recruitment process: not described

Number for analysis: 40

Informed consent: written

Setting: community

Subgroups measured: not specified

Intervention characteristics: physiotherapist-assisted walking goals set weekly in conjunction with step per day count using the activity monitor

Control: usual care, defined as usual participation in activities of daily living

Outcomes

Primary: change in percentage of time spent in sedentary, moderate, and vigorous activity under free-living conditions as measure by an accelerometer; quality of Life using the Stroke Specific Quality of Life Scale (SS-QOL); health \& wellness using: Short Warwick-Edinburgh Mental Well-being Scale (SWEMWBS)

Secondary: resting systolic and diastolic blood pressure measured using a manual blood pressure monitor; cardiovascular endurance using the six-minute walk test (6MWT); participant experience of walking intervention using qualitative methods; recruitment - how many people register interest: proportion of respondents meeting eligibility criteria; number of dropouts at randomisation, during intervention or non-intervention and at 12-week assessment. Proportion of participants with self-reported or measured cardiovascular risk factors; walking programme adherence via participant diary; physiotherapy contact time, number of face-to-face visits, number of video-conferences or phone calls

\begin{tabular}{ll}
\hline Starting date & 9 December 2016 \\
\hline Contact information & Dr Lynne Clay \\
& Address: Centre for Health, Activity and Rehabilitation Research \\
& School of Physiotherapy
\end{tabular}


ACTRN12616001733460p (Continued)

University of Otago

PO Box 56

Dunedin 9054

Country: New Zealand

Phone: +64 34795235

Email: lynne.clay@otago.au.nz

\begin{tabular}{ll}
\hline Trial name or title & SPRITE - a feasibility and pilot study (SPRITE) \\
\hline Methods & Study design: randomised controlled trial \\
& Study grouping: parallel
\end{tabular}

Aim: to determine if a novel rehabilitation programme, 'The Healthy Brain Rehabilitation Manual', for transient ischaemic attack (TIA) or minor stroke patients can be developed, using Medical Research Council guidelines for developing complex health service interventions, from an approved home-based cardiac rehabilitation programme (the 'Heart Manual'), and to undertake feasibility and pilot studies of the novel programme

Unit of allocation: computer-generated randomisation prior to recruitment, allocations concealed in sealed opaque envelopes until baseline assessments completed

Duration of participation: 12 weeks

\section{Ethical approval obtained for study: yes}

Blinding: baseline assessment blinded, post-intervention assessments not blinded

Physical activity monitor used: pedometer or Fitbit Charge

Participants

Inclusion: 18 years and older, men or women, attendee at participating TIA clinical within 4 weeks of a first suspected TIA, diagnosed with TIA or minor stroke

Exclusion: patients who have experienced more than 1 TIA or stroke, inability to give informed consent, presenting after 4 weeks of first suspected TIA or minor stroke, contra-indicated for exercise training based on guidelines of the American College of Sports Medicine

Method of recruitment: consenting attendees at TIA clinic telephoned by researchers to invite participation

\section{Number for analysis: 75}

Informed consent: yes

Setting: community

Subgroups measured: not specified

Receive usual post-TIA or minor stroke care

\section{Active comparator: manual}


Kee 2016 (Continued)

Receive usual post-TIA or minor stroke care + 'The Health brain Rehabilitation Manual' providing information regarding secondary prevention, e.g. smoking cessation, physical activity promotion

\section{Active comparator: manual + pedometer 1}

Receive usual post-TIA or minor stroke care + 'The Health brain Rehabilitation Manual' providing information regarding secondary prevention, e.g. smoking cessation, physical activity promotion + pedometer to measure step count, encouraged to keep step-count diary + telephone follow-up by general practitioner or nurse

\section{Outcomes}

Primary: rate of recruitment at 12 weeks

Secondary: change in level of physical activity (steps per day and accelerometer data), change in body mass index, change in quality of life, change in blood pressure, change in physical function (2minute walk test) baseline to 12 weeks

Rate of retention at 12 weeks

\begin{tabular}{ll}
\hline Starting date & March 2016 \\
\hline Contact information & Neil Heron nheron02@qub.ac.uk; Frank Kee f.kee@qub.ac.uk \\
\hline Notes & -
\end{tabular}

\section{Klassen 2015}

Trial name or title

Determining Optimal poststroke Exercise (DOSE)

Methods

Study design: randomised controlled trial

Study grouping: parallel

Aim: to provide preliminary evidence of efficacy of physical exercise dose on ambulatory function in adults undergoing sub-acute stroke rehabilitation

Unit of allocation: not specified

Duration of participation: 4 weeks intervention, 12 months follow-up

Ethical approval obtained for study: not specified

Blinding: participants will be blinded

Physical activity monitor used: not specified

Inclusion: admitted to hospital for stroke rehabilitation, within 10 weeks of stroke, 19 years or older, experiencing difficulty walking

Exclusion: requires more than 1 person assist for transfer or ambulation, uncontrolled medical condition or another serious medication condition in addition to stroke, unable to understand or follow directions

Method of recruitment: inpatients invited to participate

\section{Number for analysis: 75}

Informed consent: not specified

Setting: inpatient rehabilitation 


\section{Active comparator: stroke management programme}

Participants will have usual care, and in addition, be provided with periodic information about their progress with regard to mobility, using specialised activity monitors.

\section{Experimental: stroke monitoring programme}

Participants will have usual care, and in addition, be progressed according to customised protocols using feedback from specialised activity monitors.

\section{Experimental: stroke supplementary programme}

Participants will have usual care, and in addition, will receive the same as Stroke Monitoring Group and also receive 1 hour of daily (5 times per week) physical exercise.

Secondary: ambulatory function (5-Meter Walk Test, Functional Ambulation Classification), balance function (Berg Balance Scale), quality of life (EuroQol), cognition (Montreal Cognitive Assessment, Digit Symbols Substitution Test, Trail Making Test), depression (Patient Health Questionnaire-9), all at Rehabilitation discharge (average 4 to 5 weeks post admission), 6, and 12 months poststroke

Heart rate and step count measured during the intervention sessions (from 10 intervention sessions within the 4 week intervention)

\begin{tabular}{ll}
\hline Starting date & September 2013 \\
\hline Contact information & Chihya Hung, 604-714-4108, chihya.hung@ubc.ca \\
\hline Notes & - \\
\hline
\end{tabular}

\section{NCT02494245}

Aim: to compare physical activity in stroke survivors who have undertaken a four-month physical activity intervention using the STARFISH application with a control group receiving 4 months of usual care

Unit of allocation: not specified

Duration of participation: 4 months

Ethical approval obtained for study: not specified

Blinding: blinded outcome assessors

Physical activity monitor used: STARFISH app

Participants

Inclusion: 18 years and older, single unilateral stroke, discharged from active rehabilitation, able to walk independently with or without orthosis or aid, able to comprehend instruction 
Exclusion: history of serious cardiac disease in the previous 6 months, uncontrolled blood pressure, significant neurological or musculoskeletal conditions in addition to stroke, currently participating in another clinical trial (rehabilitation or pharmacological)

Method of recruitment: community clinics and health services to identify potential participants and provide them with participant information sheets

Number for analysis: 116

Informed consent: required

Setting: community

Subgroups measured: not specified
Intervention: 4-month physical activity intervention using STARFISH app with the aim of increasing physical activity by 3000 steps per day. Participants will be provided with a smartphone for the intervention. Participants will work in groups of 4, but each participant will have their own individualised step count target, based on their baseline step count. If the participant reaches their step count target on at least 5 days of the week, then their target will be increased by $5 \%$ for the following week, up to a maximum increase of 3000 steps above baseline. Where a participant fails to reach their step count target, it remains unchanged for the following week

Control: provided with booklet with general advice on physical activity
Primary: change in steps per day (baseline, 4 months, 6 months) measured with ActivPAL

Secondary: change in sedentary time measured with ActivPAL, change in 6-minute walk test, change in 10-metre walk test, change in Nottingham Extended Actvities of Daily Living Scale, change in Fatigue Severity Scale, change in Stroke Specific Quality of Life Scale, change in Hospital Anxiety and Depression Scale, change in blood pressure, change in weight in kg, change in plasma lipid profile, change in heart rate, change in walking time measured with ActivPAL, liver function, change in C-reactive protein level, change in $\mathrm{HbA1C}$ (all at baseline, 4 months, 6 months)

\begin{tabular}{ll}
\hline Starting date & July 102015 \\
\hline Contact information & Aleksandra Dybus, 0141330 5536, aleksandra.dybus@glasgow.ac.uk \\
\hline Notes & - \\
\hline
\end{tabular}

\section{NCT02587585}

Trial name or title
An international randomised clinical trial of activity feedback during inpatient stroke rehabilitation enabled by smart watches
Methods
Study design: randomised controlled trial

Study grouping: parallel

Aim: to determine the effect of augmented-activity feedback by smart watches to support in-patient stroke rehabilitation

Unit of allocation: not described

Duration of participation: 21 days or point of discharge

Ethical approval obtained for study: yes

Blinding: outcome assessor 


\section{Physical activity monitor used: smart watch}

Participants

Inclusion: admission for acute or subacute inpatient neurorehabilitation of a first stroke at the 2nd Affiliated Hospital of Anhui University of Traditional Medicine and Acupuncture, Hefei, China; time from onset of stroke to admission for rehabilitation < 16 weeks; ability to follow a 2-stage command; pick up an object, put object on table; independent in mobility prior to admission. Participants can use any type of assistive device and brace needed; able to understand and repeat information related to the informed consent

Exclusion: admission for second stroke; people who are unable to provide consent due to a cognitive impairment

Method of recruitment: via inpatient neurorehabilitation for a first stroke at the 2nd Affiliated Hospital of Anhui University of Traditional Medicine and Acupuncture, Hefei, China

Number for analysis: 200

Informed consent: written

Setting: inpatient rehabilitation

Subgroups measured: not specified

For each 2-hour epoch, the watch calculates the level of activity for the same epoch the day before, and adds $5 \%$ as the new target to be achieved

Sham comparator: no feedback

For participants assigned to the control group, the smart watch will not provide any activity feedback against a target; it simply shows which 2-hour epoch a person is in

\section{Primary}

Change in activity counts as measured by a triaxial accelerometer from a smart watch from admission to 3 weeks or discharge from rehabilitation

\section{Secondary}

Activity goal attainment as measured and provided by the smart watch at 3 weeks, or discharge if sooner

Change in walking speed and spatio temporal characteristics of walking as measured by an inertial sensor on the lower trunk during a 10-m walk test

Fatigue at baseline, 3 weeks, or discharge from inpatient rehabilitation if sooner, using the Fatigue Severity Index

Health status on EQ-5D-5L at baseline, 3 weeks, or discharge from inpatient rehabilitation if sooner, and 12 weeks (by telephone). This scale compromises 5 dimensions: mobility, self-care, usual activities, pain or discomfort, and anxiety or depression

Change in functional mobility as measured by Rivermead Mobility Index (RMI) at baseline, 3 weeks, or discharge from inpatient rehabilitation if sooner, and 12 weeks (by telephone)

Change in cognitive function as measured by the Montreal Cognitive Assessment (MoCA) at baseline, 3 weeks, or discharge from inpatient rehabilitation if sooner

Change in arm function recovery at baseline, 3 weeks, or discharge from inpatient rehabilitation if sooner, using a grip dynamometer

Change in performance of activities of daily living as measured by Barthel ADL Index at baseline, 3 weeks, or discharge from inpatient rehabilitation if sooner 
NCT02587585 (Continued)

Change in disability as measured by World Health Organisation Disability Assessment Scale (12 item version) at baseline, 3 weeks, or discharge from inpatient rehabilitation if sooner, and 12 weeks

Adverse events at 3 weeks, or discharge if sooner, and at 12 weeks, self-reported adverse events

\begin{tabular}{ll}
\hline Starting date & 27 October 2015 \\
\hline Contact information & Professor Derick T Wade, MD \\
& Oxford Brooks University \\
& Dr Yun Dong \\
& The 2nd Affiliated Hospital to Anhui University of Tranditional Chinese Medicine \\
& Hefei, Anhui, China \\
& Phone: +865516266 5048 \\
& Email: dongyun1003@126.com \\
\hline
\end{tabular}

Notes

\section{NCT02835313}

Aim: to test whether, and for whom, combining fast-walking training with a step-activity monitoring programme (FAST+SAM) is superior in improving real-world walking activity compared to fastwalking training alone (FAST) or a step-activity monitoring and feedback program alone (SAM), in those with chronic stroke

Unit of allocation: not described

Duration of participation: 12 weeks

\section{Ethical approval obtained for study: yes}

Blinding: outcome assessor

Physical activity monitor used: step-activity monitor (SAM)

Inclusion: age 21 to 85 years; chronic stroke (> 6 months post stroke); able to walk at self-selected speed without assistance from another person (assistive devices are allowed); self-selected walking speed $>0.3 \mathrm{~m} / \mathrm{s}$ and $<1.0 \mathrm{~m} / \mathrm{s}$; average steps/day $<8,000$; resting heart rate between 40 and 100 beats per minute; resting blood pressure between $90 / 60$ and $170 / 90$

Exclusion: evidence of cerebellar stroke; other potentially disabling neurologic conditions in addition to stroke; lower limb Botulinum toxin injection $<4$ months earlier; current participation in physical therapy; inability to walk outside the home prior to the stroke; coronary artery bypass graft, stent placement or myocardial infarction within past 3 months; musculoskeletal pain that limits activity; inability to communicate with investigators; score $>1$ on question $1 \mathrm{~b}$ and $>0$ on question 1c on the NIH Stroke Scale

Method of recruitment: not specified 
NCT02835313 (Continued)

\section{Number for analysis: 258}

Informed consent: written

Setting: community

Subgroups measured: not specified

Interventions

Experimental: FAST+ SAM. Individuals participate in fast-walking training in combination with a step-activity monitoring programme 3 times/week for 12 weeks

Active Comparator: FAST. Individuals participate in fast-walking training 3 times/week for 12 weeks

Active Comparator: SAM. Individuals participate in a step-activity monitoring programme 3 times/ week for 12 weeks

\begin{tabular}{ll}
\hline Outcomes & Primary \\
& Steps per day: change in steps per day from pre-intervention to 12 months later \\
Secondary \\
Walking speed as measured by the 10-metre walk test: change in walking speed from pre-interven- \\
tion to 12 months later \\
Endurance as measured by the 6-minute walk test: change in endurance from pre-intervention to \\
12 months later \\
Oxygen consumption: change in oxygen consumption from pre-intervention to 12 months later \\
\hline July 2016 \\
\hline Darcy Reisman, PT, PhD \\
University of Delaware \\
Newark, Delaware, United States, 19712 \\
Phone: $302-764-4701$ \\
Email: dreisman@udel.edu
\end{tabular}

\section{DATA AND ANALYSES}

\section{Comparison 1. Activity monitor + other intervention vs other intervention alone}

\begin{tabular}{lllll}
\hline Outcome or subgroup title & $\begin{array}{l}\text { No. of } \\
\text { studies }\end{array}$ & $\begin{array}{l}\text { No. of } \\
\text { partici- } \\
\text { pants }\end{array}$ & Statistical method & Effect size \\
\hline $\begin{array}{l}1 \text { Number of steps per day }(x 1000) \\
\text { at end of intervention }\end{array}$ & 3 & Mean Difference (IV, Random, 95\% CI) & Subtotals only \\
\hline
\end{tabular}




\begin{tabular}{|c|c|c|c|c|}
\hline Outcome or subgroup title & $\begin{array}{l}\text { No. of } \\
\text { studies }\end{array}$ & $\begin{array}{l}\text { No. of } \\
\text { partici- } \\
\text { pants }\end{array}$ & Statistical method & Effect size \\
\hline $\begin{array}{l}1.1 \text { Community dwelling (> } 6 \\
\text { months post-stroke) }\end{array}$ & 1 & 27 & Mean Difference (IV, Random, 95\% Cl) & $-1.93[-4.41,0.55]$ \\
\hline $\begin{array}{l}1.2 \text { Inpatient rehabilitation (<6 } \\
\text { months post-stroke) }\end{array}$ & 2 & 83 & Mean Difference (IV, Random, 95\% Cl) & $1.40[-0.04,2.84]$ \\
\hline $\begin{array}{l}2 \text { Time spent on light, moderate, } \\
\text { vigorous intensity activity }\end{array}$ & 1 & & Mean Difference (IV, Random, 95\% Cl) & $\begin{array}{l}\text { Totals not select- } \\
\text { ed }\end{array}$ \\
\hline 2.1 Light intensity activity & 1 & & Mean Difference (IV, Random, 95\% Cl) & $0.0[0.0,0.0]$ \\
\hline 2.2 Moderate intensity activity & 1 & & Mean Difference (IV, Random, 95\% Cl) & $0.0[0.0,0.0]$ \\
\hline 2.3 Vigorous intensity activity & 1 & & Mean Difference (IV, Random, 95\% Cl) & $0.0[0.0,0.0]$ \\
\hline $\begin{array}{l}3 \text { Total time walking at end of inter- } \\
\text { vention }\end{array}$ & 2 & & Mean Difference (IV, Random, 95\% CI) & $\begin{array}{l}\text { Totals not select- } \\
\text { ed }\end{array}$ \\
\hline $\begin{array}{l}\text { 3.1 Community dwelling (> } 6 \\
\text { months post-stroke) }\end{array}$ & 1 & & Mean Difference (IV, Random, 95\% Cl) & $0.0[0.0,0.0]$ \\
\hline $\begin{array}{l}3.2 \text { Inpatient rehabilitation }(<6 \\
\text { months post-stroke) }\end{array}$ & 1 & & Mean Difference (IV, Random, 95\% Cl) & $0.0[0.0,0.0]$ \\
\hline $\begin{array}{l}4 \text { Stroke Impact Scale-16 at end of } \\
\text { intervention }\end{array}$ & 1 & & Mean Difference (IV, Random, 95\% CI) & $\begin{array}{l}\text { Totals not select- } \\
\text { ed }\end{array}$ \\
\hline $\begin{array}{l}4.1 \text { Inpatient rehabilitation ( }<6 \\
\text { months post-stroke) }\end{array}$ & 1 & & Mean Difference (IV, Random, 95\% Cl) & $0.0[0.0,0.0]$ \\
\hline
\end{tabular}

\section{Analysis 1.1. Comparison 1 Activity monitor + other intervention vs other intervention alone, Outcome 1 Number of steps per day $(x 1000)$ at end of intervention.}

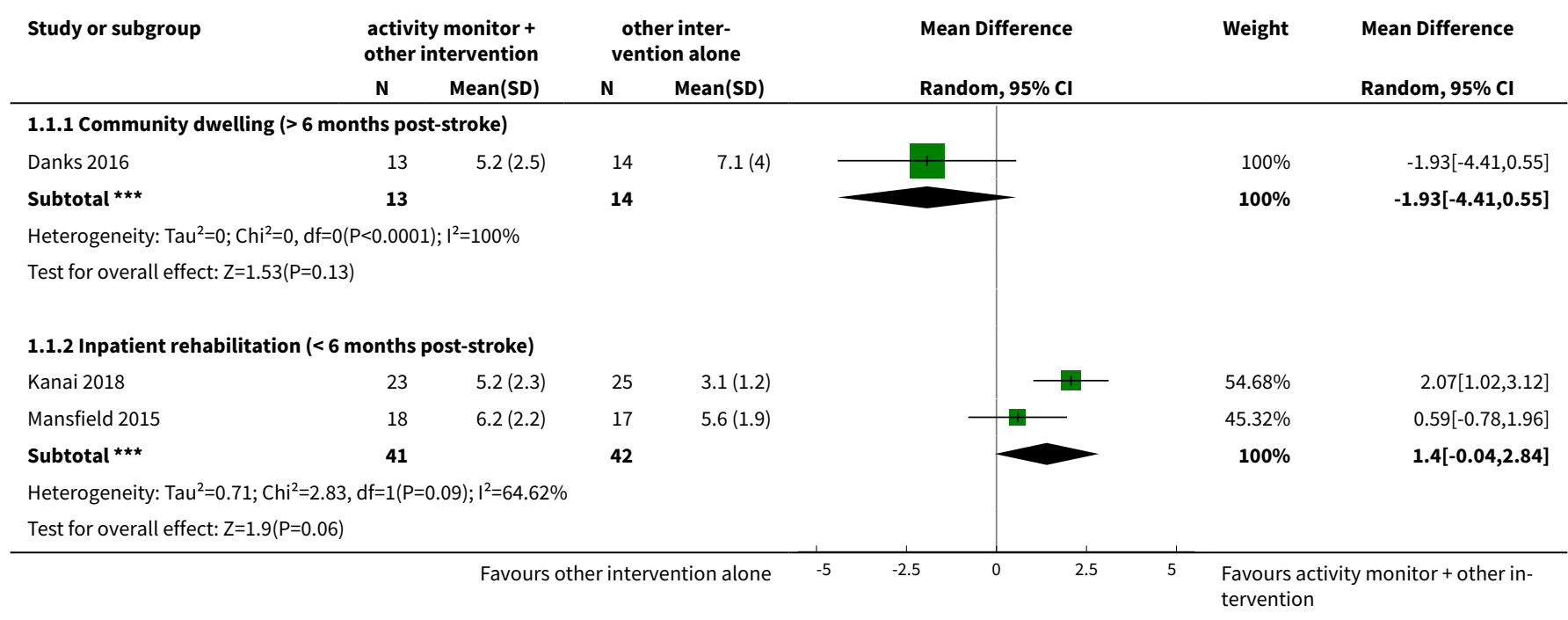


Analysis 1.2. Comparison 1 Activity monitor + other intervention vs other intervention alone, Outcome 2 Time spent on light, moderate, vigorous intensity activity.

\begin{tabular}{|c|c|c|c|c|c|c|c|c|c|}
\hline \multirow[t]{2}{*}{ Study or subgroup } & \multicolumn{2}{|c|}{$\begin{array}{l}\text { activity monitor + } \\
\text { other intervention }\end{array}$} & \multicolumn{2}{|c|}{ other intervention alone } & \multirow{2}{*}{\multicolumn{3}{|c|}{$\begin{array}{l}\text { Mean Difference } \\
\text { Random, } 95 \% \mathrm{Cl}\end{array}$}} & & \multirow{2}{*}{$\begin{array}{l}\text { Mean Difference } \\
\text { Random, } 95 \% \mathrm{Cl}\end{array}$} \\
\hline & $\mathbf{N}$ & Mean(SD) & $\mathbf{N}$ & Mean(SD) & & & & & \\
\hline & & \multicolumn{8}{|c|}{ 1.2.1 Light intensity activity } \\
\hline Kanai 2018 & 23 & $139.5(52)$ & 25 & $113.7(35.1)$ & & & & & $25.8[0.48,51.12]$ \\
\hline \multicolumn{10}{|c|}{ 1.2.2 Moderate intensity activity } \\
\hline Kanai 2018 & 23 & $7.1(9.4)$ & 25 & $2.7(3.8)$ & & & + & & $4.4[0.28,8.52]$ \\
\hline \multicolumn{10}{|c|}{ 1.2.3 Vigorous intensity activity } \\
\hline Kanai 2018 & 23 & $3.4(8.2)$ & 25 & $0.8(1.5)$ & & & + & & $2.6[-0.8,6]$ \\
\hline
\end{tabular}

Analysis 1.3. Comparison 1 Activity monitor + other intervention vs other intervention alone, Outcome 3 Total time walking at end of intervention.

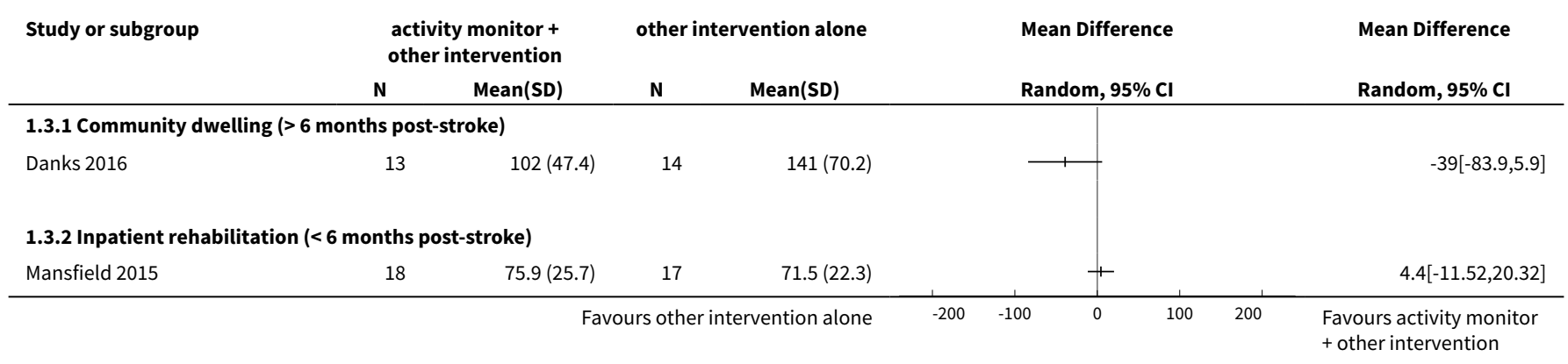

Analysis 1.4. Comparison 1 Activity monitor + other intervention vs other intervention alone, Outcome 4 Stroke Impact Scale-16 at end of intervention.

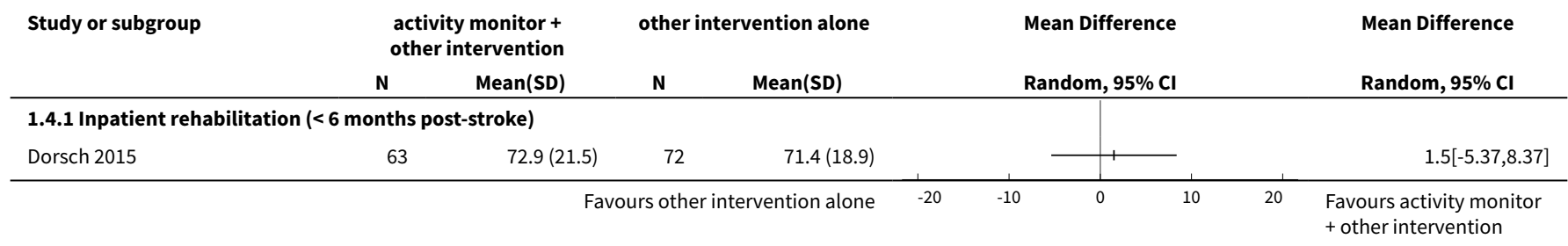

ADDITIONAL TABLES

Table 1. Outcomes reported in included studies of interest to this review

\begin{tabular}{llll}
\hline Pre-specified outcomes & $\begin{array}{l}\text { Danks } \\
2016\end{array}$ & $\begin{array}{l}\text { Dorsch } \\
2015\end{array}$ & $\begin{array}{l}\text { Kanai } \\
2018\end{array}$ \\
\hline Steps per day & $\checkmark$ & $\checkmark$ & $\checkmark$ \\
\hline
\end{tabular}


Table 1. Outcomes reported in included studies of interest to this review (Continued)

Time in moderate-vigorous physical activity

\section{Sedentary time}

Time in light physical activity

$\checkmark$

Walking duration $\quad \checkmark \quad \checkmark$

\section{Fatigue}

Mood

\section{Quality of life}

\section{Community participation}

\section{Adverse events: falls, hospitalisations, death}

Pre-specified outcomes as per review protocol (Lynch 2017)

\section{AP PEN DICES}

\section{Appendix 1. CENTRAL search strategy}

1. [mh $\wedge^{\wedge}$ "cerebrovascular disorders"] or [mh "basal ganglia cerebrovascular disease"] or [mh "brain ischemia"] or [mh "carotid artery diseases"] or [mh "intracranial arterial diseases"] or [mh "intracranial arteriovenous malformations"] or [mh "intracranial embolism and thrombosis"] or [mh "intracranial hemorrhages"] or [mh ^stroke] or [mh "brain infarction"] or [mh ^"stroke, lacunar"] or [mh

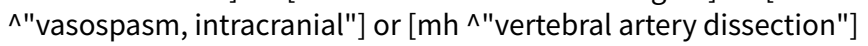

2. (stroke* or poststroke or apoplex* or cerebral vasc* or brain vasc* or cerebrovasc ${ }^{\star}$ or cva* or SAH):ti,ab,kw (Word variations have been searched)

3. ((brain or cerebr ${ }^{\star}$ or cerebell ${ }^{\star}$ or vertebrobasil ${ }^{\star}$ or hemispher ${ }^{\star}$ or intracran ${ }^{\star}$ or intracerebral or infratentorial or supratentorial or middle cerebral artery or $\mathrm{MCA}^{\star}$ or anterior circulation or posterior circulation or basilar artery or vertebral artery or space-occupying) near/5 (isch?emi* or infarct* or thrombo* or emboli* or occlus* or hypoxi $\left.{ }^{\star}\right)$ ):ti,ab,kw (Word variations have been searched)

4. ((brain* or cerebr ${ }^{\star}$ or cerebell ${ }^{\star}$ or intracerebral or intracran* or parenchymal or intraparenchymal or intraventricular or infratentorial or supratentorial or basal gangli* or putaminal or putamen or posterior fossa or hemispher ${ }^{\star}$ or subarachnoid) near/5 (h?emorrhag* or $\mathrm{h}$ ? ematoma* or bleed $\left.{ }^{\star}\right)$ :ti,ab,kw (Word variations have been searched)

5. [mh hemiplegia] or [mh paresis] or [mh "Gait Disorders, Neurologic"]

6. (hemipleg* or hemipar* or paresis or paraparesis or paretic):ti,ab,kw (Word variations have been searched)

7. $\{$ or \#1-\#6\}

8. [mh $\wedge$ feedback] or [mh "feedback, physiological"] or [mh^"feedback, sensory"]

9. [ $\mathrm{mh}^{\wedge} "$ monitoring, physiologic"] or [mh "monitoring, ambulatory"]

10. [mh ${ }^{\wedge}$ "activity tracker"] or [mh accelerometry]

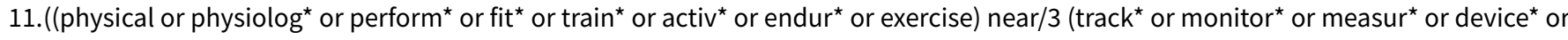
$\left.\left.\mathrm{app}^{\star}\right)\right): \mathrm{ti}, \mathrm{ab}, \mathrm{kw}$ (Word variations have been searched)

12.((step* or walk* $^{\star}$ near/3 (count* or meter $^{\star}$ or daily)):ti,ab,kw (Word variations have been searched)

13. (pedometer ${ }^{\star}$ or actigraph* or acceleromet $\left.^{\star}\right):$ ti,ab,kw (Word variations have been searched)

14. [mh^telemedicine]

15. [mh $\wedge^{\prime \prime m o b i l e ~ a p p l i c a t i o n s "] ~ o r ~[m h ~}{ }^{\wedge} "$ cell phones"] or [mh ^smartphone] or [mh ^microcomputers] or [mh ${ }^{\wedge}$ "computers, handheld"]

16. ((cell ${ }^{\star}$ or smart ${ }^{\star}$ or mobile or android or internet or web) near/3 (comput ${ }^{\star}$ or device or app ${ }^{\star}$ or phone)):ti,ab,kw (Word variations have been searched)

17. \{or \#8-\#16\}

18.\#7 and \#17 


\section{Appendix 2. MEDLINE Ovid search strategy}

1. cerebrovascular disorders/ or basal ganglia cerebrovascular disease/ or exp brain ischemia/ or exp carotid artery diseases/ or exp cerebral small vessel diseases/ or exp intracranial arterial diseases/ or exp "intracranial embolism and thrombosis"/ or exp intracranial hemorrhages/ or stroke/ or exp brain infarction/ or stroke, lacunar/ or vasospasm, intracranial/ or vertebral artery dissection/

2. (stroke\$ or poststroke or apoplex\$ or cerebral vasc\$ or brain vasc\$ or cerebrovasc\$ or cva\$ or SAH).tw.

3. ( (brain or cerebr\$ or cerebell\$ or vertebrobasil\$ or hemispher\$ or intracran\$ or intracerebral or infratentorial or supratentorial or middle cerebral artery or MCA $\$$ or anterior circulation or posterior circulation or basilar artery or vertebral artery or space-occupying) adj5 (isch? emi\$ or infarct\$ or thrombo $\$$ or emboli\$ or occlus\$ or hypoxi\$)).tw.

4. ((brain\$ or cerebr\$ or cerebell\$ or intracerebral or intracran\$ or parenchymal or intraparenchymal or intraventricular or infratentorial or supratentorial or basal gangli\$ or putaminal or putamen or posterior fossa or hemispher\$ or subarachnoid) adj5 (h?emorrhag\$ or h? ematoma\$ or bleed\$)).tw.

5. hemiplegia/ or exp paresis/ or exp Gait Disorders, Neurologic/

6. (hemipleg\$ or hemipar\$ or paresis or paraparesis or paretic).tw.

7. or/1-6

8. feedback/ or exp feedback, physiological/ or feedback, sensory/

9. monitoring, physiologic/or exp monitoring, ambulatory/

10. activity tracker/ or exp accelerometry/

11. ((physical or physiolog\$ or perform $\$$ or fit $\$$ or train $\$$ or activ\$ or endur\$ or exercise) adj3 (track\$ or monitor\$ or measur\$ or device\$ or app\$)).tw.

12. ((step\$ or walk\$) adj3 (count\$ or meter\$ or daily)).tw.

13. (pedometer\$ or actigraph\$ or acceleromet\$).tw.

14. telemedicine/

15. Mobile Applications/ or cell phones/ or smartphone/ or microcomputers/ or computers, handheld/

16. ((cell\$ or smart\$ or mobile or android or internet or web) adj3 (comput\$ or device or app\$ or phone)).tw.

17. or/8-16

18. Randomized Controlled Trials as Topic/

19. Random Allocation/

20. Controlled Clinical Trials as Topic/

21. control groups/

22. clinical trials as topic/ or clinical trials, phase i as topic/ or clinical trials, phase ii as topic/ or clinical trials, phase iii as topic/ or clinical trials, phase iv as topic/

23. double-blind method/

24. single-blind method/

25. Placebos/

26. placebo effect/

27. cross-over studies/

28. randomized controlled trial.pt.

29. controlled clinical trial.pt.

30. (clinical trial or clinical trial phase i or clinical trial phase ii or clinical trial phase iii or clinical trial phase iv).pt.

31. (random\$ or RCT or RCTs).tw.

32. (controlled adj5 (trial\$ or stud\$)).tw.

33. (clinical\$ adj5 trial\$).tw.

34. ((control or treatment or experiment\$ or intervention) adj5 (group\$ or subject\$ or patient\$)).tw.

35. (quasi-random $\$$ or quasi random\$ or pseudo-random $\$$ or pseudo random\$).tw.

36. ((control or experiment\$ or conservative) adj5 (treatment or therapy or procedure or manage\$)).tw.

37. ((singl\$ or doubl\$ or tripl\$ or trebl\$) adj5 (blind\$ or mask\$)).tw.

38. (cross-over or cross over or crossover).tw.

39. (placebo $\$$ or sham).tw.

40. trial.ti.

41. (assign\$ or allocat\$).tw.

42. controls.tw.

43. or $/ 18-42$

44. 7 and 17 and 43

\section{Appendix 3. Embase search strategy}

1. cerebrovascular disease/ or brain disease/ or exp basal ganglion hemorrhage/ or exp brain hemangioma/ or exp brain hematoma/ or exp brain hemorrhage/ or exp brain infarction/ or exp brain ischemia/ or exp carotid artery disease/ or exp cerebral artery disease/ or exp cerebrovascular accident/ or exp cerebrovascular malformation/ or exp intracranial aneurysm/ or exp occlusive cerebrovascular disease/ or exp vertebrobasilar insufficiency/

2. (stroke\$ or poststroke or apoplex\$ or cerebral vasc\$ or brain vasc\$ or cerebrovasc\$ or cva\$ or SAH).tw. 
3. ((brain or cerebr\$ or cerebell\$ or vertebrobasil\$ or hemispher\$ or intracran\$ or intracerebral or infratentorial or supratentorial or middle cerebral artery or MCA $\$$ or anterior circulation or posterior circulation or basilar artery or vertebral artery or space-occupying) adj5 (isch? emi\$ or infarct\$ or thrombo\$ or emboli\$ or occlus\$ or hypoxi\$)).tw.

4. ((brain\$ or cerebr\$ or cerebell\$ or intracerebral or intracran\$ or parenchymal or intraparenchymal or intraventricular or infratentorial or supratentorial or basal gangli\$ or putaminal or putamen or posterior fossa or hemispher\$ or subarachnoid) adj5 (h?emorrhag\$ or h? ematoma\$ or bleed\$)).tw.

5. exp hemiplegia/ or exp paresis/ or neurologic gait disorder/

6 . (hemipleg $\$$ or hemipar $\$$ or paresis or paraparesis or paretic).tw.

7. or/1-6

8. feedback system/or monitor/ or ambulatory monitoring/ or self monitoring/or personal monitor/or personal monitoring/or physiologic monitoring/ or exp sensory feedback/

9. exp mobile phone/ or smartphone/ or mobile application/

10. computer/ or microcomputer/ or minicomputer/ or personal digital assistant/

11. telemedicine/ or telehealth/ or medical device/ or devices/

12. ((cell\$ or smart\$ or mobile or android or internet or web) adj3 (comput\$ or device or app\$ or phone)).tw.

13. accelerometer/ or accelerometry/or actimetry/or pedometer/

14. ((physical or physiolog\$ or perform\$ or fit\$ or train\$ or activ\$ or endur\$ or exercise) adj3 (track\$ or monitor\$ or measur\$ or device\$ or app\$)).tw.

15. ((step\$ or walk\$) adj3 (count\$ or meter\$ or daily)).tw.

16. (pedometer\$ or actigraph\$ or acceleromet\$).tw.

17. or/8-16

18. Randomized Controlled Trial/ or "randomized controlled trial (topic)"/

19. Randomization/

20. Controlled clinical trial/ or "controlled clinical trial (topic)"/

21. control group/ or controlled study/

22. clinical trial/ or "clinical trial (topic)"/ or phase $1 \mathrm{clinical}$ trial/ or phase 2 clinical trial/ or phase $3 \mathrm{clinical}$ trial/ or phase $4 \mathrm{clinical}$ trial/

23. Crossover Procedure/

24. Double Blind Procedure/

25. Single Blind Procedure/ or triple blind procedure/

26. placebo/ or placebo effect/

27. (random\$ or RCT or RCTs).tw.

28. (controlled adj5 (trial\$ or stud\$)).tw.

29. (clinical\$ adj5 trial\$).tw.

30. ((control or treatment or experiment\$ or intervention) adj5 (group\$ or subject\$ or patient\$)).tw.

31. (quasi-random $\$$ or quasi random $\$$ or pseudo-random $\$$ or pseudo random $\$$ ).tw.

32. ((control or experiment\$ or conservative) adj5 (treatment or therapy or procedure or manage\$)).tw.

33. ((singl\$ or doubl\$ or tripl\$ or trebl\$) adj5 (blind\$ or mask\$)).tw.

34. (cross-over or cross over or crossover).tw.

35. (placebo\$ or sham).tw.

36. trial.ti.

37. (assign\$ or allocat\$).tw.

38. controls.tw.

39. or/18-38

40.7 and 17 and 39

\section{Appendix 4. CINAHL search strategy}

1. (MH "Cerebrovascular Disorders") OR (MH "Basal Ganglia Cerebrovascular Disease+") OR (MH "Carotid Artery Diseases+") OR (MH "Cerebral Ischemia+") OR (MH "Cerebral Vasospasm") OR (MH "Intracranial Arterial Diseases+") OR (MH "Intracranial Embolism and Thrombosis") OR (MH "Intracranial Hemorrhage+") OR (MH "Stroke") OR (MH "Vertebral Artery Dissections")

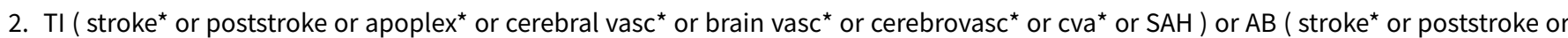
apoplex ${ }^{\star}$ or cerebral vasc ${ }^{\star}$ or brain vasc ${ }^{\star}$ or cerebrovasc ${ }^{\star}$ or cva* $^{\star}$ or SAH )

3. TI ( brain or cerebr ${ }^{\star}$ or cerebell* or vertebrobasil ${ }^{\star}$ or hemispher $^{\star}$ or intracran ${ }^{\star}$ or intracerebral or infratentorial or supratentorial or middle cerebral artery or $\mathrm{MCA}^{\star}$ or anterior circulation or posterior circulation or basilar artery or vertebral artery or space-occupying ) or $\mathrm{AB}$ ( brain or cerebr ${ }^{\star}$ or cerebell* or vertebrobasil ${ }^{\star}$ or hemispher ${ }^{\star}$ or intracran* or intracerebral or infratentorial or supratentorial or middle cerebral artery or $\mathrm{MCA}^{\star}$ or anterior circulation or posterior circulation or basilar artery or vertebral artery or space-occupying )

4. $\mathrm{TI}$ ( ischemi ${ }^{\star}$ or ischaemi ${ }^{\star}$ or infarct ${ }^{\star}$ or thrombo ${ }^{\star}$ or emboli ${ }^{\star}$ or occlus ${ }^{\star}$ or hypoxi ${ }^{\star}$ ) or AB (ischemi ${ }^{\star}$ or ischaemi or infarct $^{\star}$ or thrombo $^{\star}$ or emboli* or occlus* or hypox* )

5. S3 and S4

6. $\mathrm{TI}$ ( brain $^{\star}$ or cerebr ${ }^{\star}$ or cerebell ${ }^{\star}$ or intracerebral or intracran ${ }^{\star}$ or parenchymal or intraparenchymal or intraventricular or infratentorial or supratentorial or basal gangli ${ }^{\star}$ or putaminal or putamen or posterior fossa or hemispher or subarachnoid ) or $A B$ ( brain ${ }^{\star}$ or cerebr ${ }^{\star}$ 
or cerebell* or intracerebral or intracran* or parenchymal or intraparenchymal or intraventricular or infratentorial or supratentorial or basal gangli* or putaminal or putamen or posterior fossa or hemispher ${ }^{\star}$ or subarachnoid )

7. $\mathrm{TI}$ ( haemorrhage* or hemorrhage* or haematoma* or hematoma* or bleed ${ }^{\star}$ ) or AB ( haemorrhage* or hemorrhage* or haematoma* or hematoma* or bleed*)

8. $\mathrm{S} 6$ and $\mathrm{S} 7$

9. (MH "Hemiplegia")

10.TI ( hemipleg* or hemipar* or paresis or paretic ) or AB ( hemipleg* or hemipar* or paresis or paretic)

11.S1 OR S2 OR S5 OR S8 OR S9 OR S10

12. (MH "Wearable Sensors") OR (MH "Accelerometers") OR (MH "Pedometers") OR (MH "Monitoring, Physiologic") OR (MH "Actigraphy")

13. (MH "Computers, Portable+") OR (MH "Minicomputers") OR (MH "Microcomputers") OR (MH "Telehealth") OR (MH "Cellular Phone+")

14.(MH "Feedback") OR (MH "Biofeedback")

15. TI ( ((physical or physiolog* or perform ${ }^{\star}$ or fit ${ }^{\star}$ or train ${ }^{\star}$ or activ ${ }^{\star}$ or endur ${ }^{\star}$ or exercise) N3 (track* or monitor ${ }^{\star}$ or measur or device $^{\star}$ or app $\left.^{\star}\right)$ ) ) OR AB ( ((physical or physiolog* or perform ${ }^{\star}$ or fit ${ }^{\star}$ or train ${ }^{\star}$ or activ ${ }^{\star}$ or endur ${ }^{\star}$ or exercise) N3 (track ${ }^{\star}$ or monitor ${ }^{\star}$ or measur $^{\star}$ or device* or app $\left.\left.{ }^{\star}\right)\right)$ )

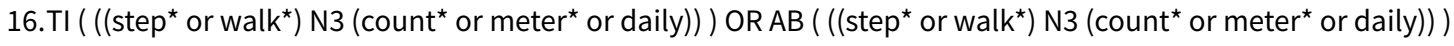

17. TI ( (pedometer ${ }^{\star}$ or actigraph ${ }^{\star}$ or acceleromet $\left.{ }^{\star}\right)$ ) OR AB ( (pedometer or actigraph $^{\star}$ or acceleromet $\left.^{\star}\right)$ )

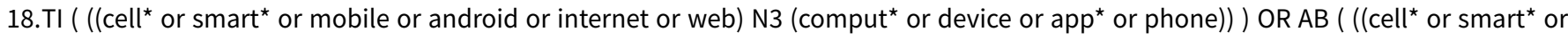
mobile or android or internet or web) N3 (comput* or device or app* or phone)) )

19.S12 OR S13 OR S14 OR S15 OR S16 OR S17 OR S18

20.(MH "Randomized Controlled Trials") or (MH "Random Assignment") or (MH "Random Sample+")

21.(MH "Clinical Trials") or (MH "Intervention Trials") or (MH "Therapeutic Trials")

22. (MH "Double-Blind Studies") or (MH "Single-Blind Studies") or (MH "Triple-Blind Studies")

23. (MH "Control (Research)") or (MH "Control Group") or (MH "Placebos") or (MH "Placebo Effect")

24.(MH "Crossover Design") OR (MH "Quasi-Experimental Studies")

25.PT (clinical trial or randomized controlled trial)

26.TI (random* or RCT or RCTs) or AB (random* or RCT or RCTs)

27. TI (controlled N5 (trial* or stud $\left.\left.{ }^{\star}\right)\right)$ or AB (controlled N5 (trial* or stud $\left.{ }^{\star}\right)$ )

28. TI (clinical ${ }^{\star} \mathrm{N} 5$ trial $\left.^{\star}\right)$ or AB (clinical ${ }^{\star} \mathrm{N} 5$ trial $\left.^{\star}\right)$

29. TI ((control or treatment or experiment* or intervention) N5 (group ${ }^{\star}$ or subject ${ }^{\star}$ or patient $\left.{ }^{\star}\right)$ ) or AB ((control or treatment or experiment ${ }^{\star}$ or intervention) N5 (group* or subject* or patient*))

30.((control or experiment* or conservative) N5 (treatment or therapy or procedure or manage $\left.{ }^{\star}\right)$ ) or $A B$ ((control or experiment* or conservative) N5 (treatment or therapy or procedure or manage $\left.{ }^{\star}\right)$ )

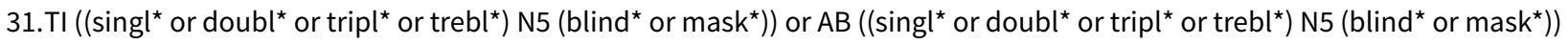

32. $\mathrm{TI}$ (cross-over or cross over or crossover) or $\mathrm{AB}$ (cross-over or cross over or crossover)

33.TI (placebo* or sham) or AB (placebo* or sham)

34.TI trial

35.TI (assign* or allocat ${ }^{\star}$ ) or AB (assign ${ }^{\star}$ or allocat ${ }^{\star}$ )

36. TI controls or $\mathrm{AB}$ controls

37. $\mathrm{TI}$ (quasi-random* or quasi random* or pseudo-random* or pseudo random) or $\mathrm{AB}$ (quasi-random* or quasi random* or pseudorandom* ${ }^{\star}$ or pseudo random*)

38.S20 OR S21 OR S22 OR S23 OR S24 OR S25 OR S26 OR S27 OR S28 OR S29 OR S30 OR S31 OR S32 OR S33 OR S 34 OR S 35 OR S36 OR S37

39.S11 AND S19 AND S38

\section{Appendix 5. SPORTDiscus search strategy}

1. DE "CEREBROVASCULAR disease" OR DE "BRAIN -- Hemorrhage" OR DE "CEREBRAL embolism \& thrombosis" OR DE "STROKE" OR DE "BRAIN -- Wounds \& injuries" OR DE "BRAIN damage" OR DE "CEREBROVASCULAR disease -- Patients"

2. $\mathrm{TI}$ ( stroke or poststroke or post-stroke or cerebrovasc* or brain vasc* or cerebral vasc or cva or apoplex or SAH ) or AB ( $s$ troke or poststroke or post-stroke or cerebrovasc ${ }^{\star}$ or brain vasc ${ }^{\star}$ or cerebral vasc or cva or apoplex or SAH )

3. ( $\mathrm{TI}$ ( brain* or cerebr ${ }^{\star}$ or cerebell ${ }^{\star}$ or intracran* or intracerebral ) or AB ( brain* or cerebr ${ }^{\star}$ or cerebell* or intracran* or intracerebral ) ) and ( $\mathrm{TI}$ ( ischemi ${ }^{\star}$ or ischaemi ${ }^{\star}$ or infarct ${ }^{\star}$ or thrombo* or emboli* or occlus ${ }^{\star}$ ) or AB (ischemi ${ }^{\star}$ or ischaemi ${ }^{\star}$ or infarct $^{\star}$ or thrombo* $^{\star}$ or emboli* or occlus* $\left.{ }^{\star}\right)$ )

4. ( $\mathrm{TI}$ ( brain ${ }^{*}$ or cerebr ${ }^{*}$ or cerebell ${ }^{\star}$ or intracerebral or intracranial or subarachnoid) or AB ( brain* or cerebr* or cerebell ${ }^{\star}$ or intracerebral or intracranial or subarachnoid)) and ( $\mathrm{TI}$ ( haemorrhage* or hemorrhage* or haematoma* or hematoma* or bleed ${ }^{\star}$ ) or AB ( haemorrhage* or hemorrhage* or haematoma* or hematoma* or bleed* ) ) 
5. DE "HEMIPLEGIA" OR DE "HEMIPLEGICS" OR DE "GAIT disorders"

6. $\mathrm{TI}$ ( hemipleg* or hemipar* or paresis or paretic ) or AB ( hemipleg* or hemipar ${ }^{\star}$ or paresis or paretic )

7. S1 OR S2 OR S3 OR S4 OR S5 OR S6

8. DE "PATIENT monitoring" OR DE "PATIENT self-monitoring"

9. DE "SMARTPHONES" OR DE "MOBILE apps"

10.DE "PHYSICAL activity -- Measurement" OR DE "EQUIPMENT \& supplies" OR DE "AUTOMATIC tracking" OR DE "WEARABLE technology" OR DE "ACCELEROMETERS" OR DE "PEDOMETERS" OR DE "MOTION detectors" OR DE "MEDICAL technology"

11.TI ( ( (physical or physiolog* or perform ${ }^{\star}$ or fit ${ }^{\star}$ or train* or activ* or endur ${ }^{\star}$ or exercise) N3 (track* or monitor ${ }^{\star}$ or measur* or device* or $\left.\mathrm{app}^{\star}\right)$ ) ) OR AB ( ((physical or physiolog* or perform* or fit ${ }^{\star}$ or train ${ }^{\star}$ or activ* or endur ${ }^{\star}$ or exercise) N3 (track or monitor $^{\star}$ or measur $^{\star}$ or device* or app*)) )

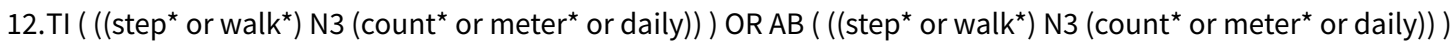

13. TI ( (pedometer ${ }^{\star}$ or actigraph* or acceleromet $\left.{ }^{\star}\right)$ ) OR AB ( (pedometer ${ }^{\star}$ or actigraph $^{\star}$ or acceleromet $\left.^{\star}\right)$ )

14. TI ( ((cell ${ }^{\star}$ or smart* or mobile or android or internet or web) N3 (comput* or device or app* or phone)) ) OR AB ( ((cell* or smart* or mobile or android or internet or web) N3 (comput* or device or app* or phone)) )

15.S8 OR S9 OR S10 OR S11 OR S12 OR S13 OR S14

16.S7 AND S15

\section{Appendix 6. Trial register search strategy}

1. Stroke AND "activity monitor"

2. Stroke AND "mobile phone"

3. Stroke AND "app"

WHAT'S NEW

\begin{tabular}{lll}
\hline Date & Event & Description \\
\hline 14 October 2019 & Amended & 'Declarations of interest' section amended \\
\hline
\end{tabular}

\section{CONTRIBUTIONSOF AUTHORS}

DS, EL, TJ, LJ, NF, SKu, SKr, CE, MC, KB, HJ, NM reviewed titles and abstracts

LJ, NF, DS, MC, HJ, EL, TJ reviewed full text articles

TJ created data extraction template in Covidence

TJ, KB, SKr, EL extracted data from included studies

TJ, SKr, LJ, EL assessed risk of bias of included studies

SKr, CE, SKu, EL analysed the data

SKr, KB performed GRADE assessment

EL, NF drafted Results

EL, KB, NM, TMJ, LJ drafted Discussion

EL, NF drafted Conclusions and Implications for Practice

SKu drafted Plain Language Summary

MC drafted abstract

CE proof-read and edited final draft

DS collected and recorded data regarding ongoing studies 
All authors read and reviewed the completed draft.

\section{DECLARATIONSOF INTEREST}

EAL: none known.

KB: none known.

$M C$ : none known.

NF: none known.

$\mathrm{HJ}$ : none known.

LJ: none known.

TMJ: none known.

SKr: none known.

SKu: none known.

NM: none known.

DS: none known.

CE: none known.

The ACTIOnS collaboration is an informal network of researchers working in physical activity and stroke. It does not receive any funding.

\section{SOURCES OF SUPPORT}

\section{Internal sources}

- University of Adelaide, Australia.

in-kind support received by E Lynch

- The Florey Institute of Neuroscience and Mental Health, University of Melbourne, Australia.

In-kind support received by E Lynch, K Borschmann, S Kramer, L Johnson

- Macquarie University, Australia.

In-kind support received by $\mathrm{T}$ Jones

- University of Tasmania, Australia.

In-kind support received by D Simpson, M Callisaya

- University of Melbourne, Australia.

In-kind support received by N Fini

- La Trobe University, Australia.

In-kind support received by N Fini

- Australian Catholic University, Australia.

In-kind support received by S Kuys

- University of Canberra, Australia.

In-kind support received by N Mahendran

- University of Newcastle, Australia.

In-kind support received by $\mathrm{H}$ Janssen, $\mathrm{C}$ English

- Hunter New England Health, Australia.

In-kind support received by $\mathrm{H}$ Janssen

\section{External sources}

- National Health and Medical Research Council, Australia.

This work was supported by NHMRC grant numbers 1077898 and 1138515

\section{DIFFERENCES BETWEEN PROTOCOL AND REVIEW}

Due to the small number of included studies, we were not able to perform the planned subgroup or sensitivity analyses. 
We only identified individually randomised trials for this review, so we did not need to analyse for unit-of-analysis issues as planned in our review protocol (Lynch 2017).

\section{INDEX TERMS}

\section{Medical Subject Headings (MeSH)}

*Exercise; *Fitness Trackers; *Survivors; Randomized Controlled Trials as Topic; Stroke Rehabilitation [*instrumentation] [methods]; Time Factors

\section{MeSH check words}

Adult; Aged; Aged, 80 and over; Humans; Middle Aged; Young Adult 